D. P. Sanchez ${ }^{a}$

August 1992

\title{
Fusion Safety Program
}

EG\&G Idaho, Inc.

Idaho National Engineering Laboratory

\author{
Prepared for the \\ U.S. Department of Energy \\ Office of Enurgy Research \\ Under DOE Idaho Field Office \\ Contract DE-AC07-76ID01570
}

a. Quality Operations Office, Los Alamos National Laboratory 
This report gives the failure rates for the major tritium containing glovebox systems that comprise the secondary Containment system at the Tritium Systems Test Assembly, which is a fusion research and technology : facility at the Los Alamos National Laboratory. The component failure reports, the numbers of components, and operating times or demands are alic given in this report, and sample calculations of the binomial demand failure rates and poisson hourly failure rates are given in the appendices. The faiiure rates for these components form a solid data point based on actual operating experience, where there is very little published information. The eight years of nearly continuous secondary Containment system operations should result in steady state failure rate values. These data should be useful for future fusion reactor design work and safety assessment tasks. 
This report outlines the operating experiences and failure rates for the Secondary Containment System (SEC) at the Tritium Systems Test Assembly (TSTA). These gloveboxes, double walled piping, pressure control systems, and monitors are typical of the equipment used in many scientific research and process applications. The failure rate and failure probability data obtained from TSTA are applicable to gloveboxes of welded stainless steel or aluminum, with polycarbonate windows, $0.76-\mathrm{mm}$ thick: gloves, operated with an inert cover gas near atmospheric pressure.

Operating experiences for more than twelve glovebox units over eight years have been examined. Operating times and failure reports were analyzed and reduced to give point estimate failure rates and uncertainty bounds for several different failure modes. Some safety calculations have been performed to estimate glovebox responses to severe overpressure, such as a hydrogen deflagration (combustion) or detonation (explosion), and estimates of the failure probability for glovebox breach during small tritium release events from the process piping and from tritium loading/unloading operations. The results are given in Table S-1.

The results of this data analysis compare favorably to published information. The failure rates for the gloveboxes are small, and the failure probabilities for gloveboxes iailing to contain iritium when necessary are lower than the scoping probabilities that have been used for recent safety assessments. Glove failure rates are much smaller than those used in other nuclear applications.

These data are applicable to the next generation fusion facilities because TSTA uses state-of-the-art technology and equipment for tritium handling, and TSTA is large enough to serve as a prototype tritium storage, processing, and handlina facility for supporting a large fusion experiment, such as the International Thermonuclear Expeririental Reactor (ITER). TSTA processes up to 130 grams of tritium a day, and can run for extended periods of up to several weeks per processing run. 
TABLE S-1. TSTA GLOVEBOX FAILURE RATE RESULTS

\begin{tabular}{|c|c|c|}
\hline Description of Failure Mode & $\begin{array}{l}\text { Point Estimate } \\
\text { Failure Rate }\end{array}$ & $\begin{array}{l}95 \% \text { Upper Bound } \\
\text { Failure Rate }\end{array}$ \\
\hline Glovebox overpressure & $0.3 /$ glovebox-year & $0.4 / g$ lovebox-year \\
\hline Glovebox underpressure & $0.2 /$ glovebox-year & $0.3 /$ glovebox-year \\
\hline Glovebox continuous purging & $0.04 /$ glovebox-year & $0.1 /$ glovebox-year \\
\hline $\begin{array}{l}\text { Air inleakage events } \\
\text { (one year of operation) }\end{array}$ & $0.1 /$ glovebox-year & $0.5 /$ glovebox-year \\
\hline $\begin{array}{l}\text { Small, external tritium } \\
\text { release events (over } 7 \text { yrs) }\end{array}$ & $0.04 /$ glovebox-year & $0.1 / g$ lovebox-year \\
\hline $\begin{array}{l}\text { Solenoid purge valve } \\
\text { fails to close on demand }\end{array}$ & $6 E-06 /$ demand & $3 E-05 /$ demand \\
\hline Oxygen monitor fails & $0.5 /$ monitor-year & $1 /$ monitor-year \\
\hline Overall glove breaches & $0.05 /$ glove-year & $0.06 /$ glove-year \\
\hline
\end{tabular}

The TSTA frequency for glovebox fires, explosions, or severe overpressure situations is calculated to be 3E-03/glovebox-year, based on 79 glovebox-years ( 8 facility years) of operations without any of these catastrophic events having occurred

\section{Probabilities for TSTA Gloveboxes}

5E-03/demand - Point estimate probability that glovebox confinement will permit tritium to escape from a small, internal tritium leak

1.0 probability of glovebox window breach -4.4 to $8.8 \mathrm{kPa}$ sudden differential overpressures (millisecond to seconds time scale), will likely breach the glovebox, for $6.4-\mathrm{mm}$ thick polycarbonate windows

1.0 probability of glove breach $-6.9 \mathrm{kPa}$ slow building differential overpressure over minutes, such as from small leakage from a high pressure gas line or a cryogen boiloff leak. (this is a reasonable approximation for glovebox failure by a glove sleeve tear)

2E-02/operation - Probability for accidental release of tritium during a container loading or unloading operation at the TSTA loading glovebox 


\section{ACKNOWLEDGMENTS}

This work would not have been possible without the cooperation of the Tritium Systems Test Assembly personnel, especially Ms. Mary King and Mr. John Miller. Their help with this work is greatly appreciated. Without the operator's diligence to uphold the 'proof of reliability' portion of the TSTA mission, there would be no failure reports in the report collection system available to support this task. The authors also want to thank Ms. Kathleen Gruetzmacher, LANL, for setting up this data bank, and the TSTA operations staff for continuing to fill out failure report forms. Failure rate data collection and analysis is funded by U.S. International Thermonuclear Experimental Reactor safety research. 
ABSTRACT .............................

SUMMARY ..................................

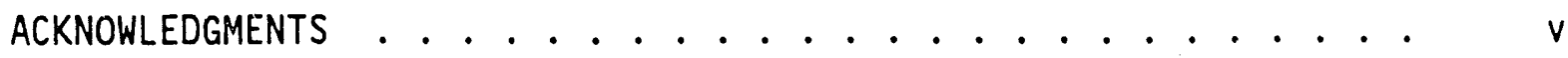

NOMENCLATURE ..................................... vii

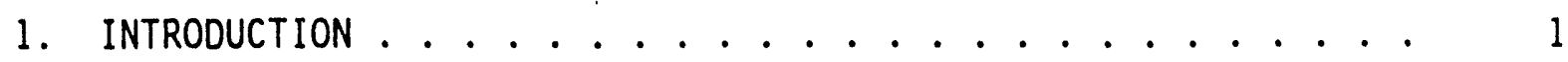

2. TSTA FAILURE/MAINTENANCE DATA BASE . . . . . . . . 2

3. SECONDARY CONTAINMENT SYSTEM DESCRIPTION . . . . . . . . . 4

4. SECONDARY CONTAINMENT SYSTEM FAILURE DATA ANALYSIS . . . . . 20

5. RESULTS COMPARISON TO OTHER GLOVEBOX EXPERIENCES . . . . . . 29

6. REFERENCES ............................ 32

APPENDIX A. STATISTICS FOR FAILURE RATES . . . . . . . . A-1

APPENDIX B. SUMMARY DESCRIPTIONS OF SECONDARY CONTAINMENT SYSTEM FAILURE REPORTS FROM 1984 TO $1991 \ldots$. . . . B- 1

APPENDIX C. TSTA FAILURE/MAINTENANCE DATA FORMS ........ c c-1

APPENDIX D. SOME SAFETY CALCULATIONS FOR TSTA GLOVEBOXES ... . D-i 


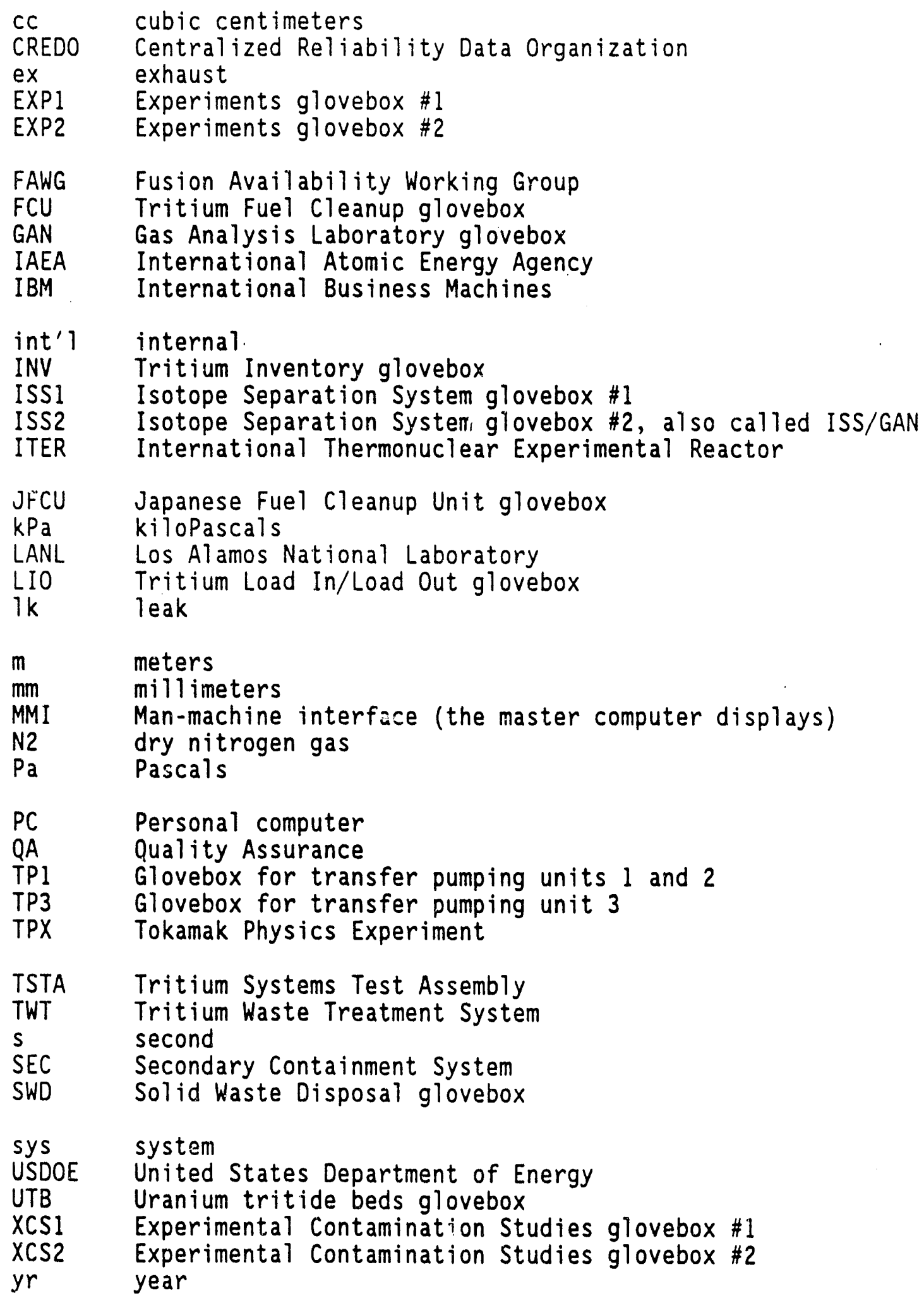




\section{INTRODUCTIONN}

This report is a summary of data collected at the Tritium Systems Test Assembiy (TSTA), at Los Alamos National Laboratory (LANL), between 1984 and 1991 that pertain to the Secondary Containment System (SEC). These failure data analysis tasks are performed to support fusion design studies and device construction. These analysis tasks are ongoing at TSTA and at the Idaho National Engineering Laboratory's Fusion Safety Program (FSP).

These data will apply to fusion systems that use the same or similar glovebox confinement around tritium piping. This report describes the operating experiences of more than a dozen gloveboxes over an 8-yr period at TSTA. This work can apply to the International Thermonuclear Experimental Reactor (ITER) design and possibly the proposed Tokamak Physics Experiment (TPX) design. This data analysis task was possible because component populations, operating times, and failures are known. The failure event reports are collected and stored in a personal computerbased program at TSTA. The data base is described in references 1 and 2 .

The SEC surrounds the various tritium systems at TSTA, with the exception of large equipment, such as the cryogenic distillation columns, which are secondarily contained by vacuum jackets. The gloveboxes house a tritium loading/unloading station, tritium transfer pumps, uranium storage beds, fuel cleanup, waste disposal, gas analysis equipment, and many tritium-related experiments conducted at TSTA. The SEC was chosen for analysis because it is a safety system and it is important to safety work for future reactor design studies and regulatory compliance documents.

The following chapters give a brief description of the TSTA failure data base, describe the SEC components, the data analysis results, and compare the results to other glovebox information from the literature. 


\section{TSTA FAILURE/MAINTEN/NCE DATA BASE}

The failure/maintenance data system at TSTA is based on the Centralized Reliability Data Organization (CREDO), ${ }^{3.4}$ a system developed at Oak Ridge National Laboratory for fast reactor failure data. CREDO's development as a national reliability data base and data analysis center for advanced fission reactors was initiated in 1978 and is funded by the U.S. Department of Energy (USDOE). CREDO was selected as the basis for a failure/maintenance data system for fusion after consideration by the informal U. S. Fusion Availability Working Group (FAWG). CREDO is a component-oriented data base that was implemented at TSTA using an IBM PC. The original objectives of the CREDO project at TSTA included:

Adapting CREDO for use in fusion availability/reliability programs

Programming the data base on the IBM PC with Knowledgeman software

Collecting the appropriate data on systems at TSTA

Testing the adapted data base with these data

Minor changes in the original CREDO data collection forms were made to make them more applicable for fusion systems.

The IBM PC was programmed using logical tables to contain the data. ${ }^{4.5}$ Three types of data are entered into the data base. These are: engineering data, event data, and component operating data. The engineering data describes each component of a system as fully as possible by involving a one-time submission of data, such as component type, model number, and operating parameters. The engineering data report uses a unique identifying number to track the component through its 1 ifetime. The event data describes each reportable event or failure in any TSTA system, and uses a unique event report number fur each event. Reporta_le events include component failures, events that lead to unscheduled repair or maintenance, and unanticipated changes in normal operating conditions 
due to a component failure. The operating data is a quarterly report that gives the operating time for the entire facility. Component operating time estimates are obtained from these overall facility values.

After the engineering data are collected on the major components in a system, event data reports becume the focus of the effort for collection of failure/maintenance data. At TSTA, two-part event data forms are strategically placed in holders throughout the facility, so that when a reportable event occurs, the forms are easily accessible by the operator involved in the event. The system operator or system designer fills out Part I of the form (example forms are given in Appendix $C$ ) whenever a component of a TSTA system fails or needs major adjustment. When the initial report is completed as much as possible, it is put back in a holder. The Quality Assurance (QA). specialists, L. A. Quintana and $D$. P. Sanchez, inspect the holders periodically and retrieve any completed forms. Part II of the form details the corrective action taken on the problem. The QA specialists route the completed Part I farms to appropriate personnel. The corrective actions are documented by either the operator, the technician repairing the component, or the system designer during or immediately after the repair/replacement of the failed. component. Then, the QA specialists pick up Part II of the form and enter this new information into the data base and assign a sequential report number. If the information is complete, the report is termed "closed". If it is incomplete, the report is termed "open" and it is returned to the appropriate personnel for completion.?

Currently, the TSTA data base has a total of more than 520 reports. These failure reports originate from all of the TSTA systems. There is a small time lag, usually a few days, between completing Parts I and II of the form. There is also a small time lag, perhaps a week or more, between completion of Part II and entry into the data base. Small time lags such as these are not uncommon. Time lags are found in all major installations, including nuclear power plants and chenical process plants, and can be up to months in duration. 


\section{SECONDARY CONTAINMENT SYSTEM DESCRIPTION}

The TSTA facility is well described in reference 6 . TSTA construction was completed in 1983, and pretritium introduction testing was performed in 1983 and early 1984. The facility performed its first tritium run on June 25, 1984. Glovebox operations began during the testing phase, so the entire calendar year of 1984 is included in operation time estimates. Some of the gloveboxes were operating in early 1984 (see Appendix B), so this is a conservative assumption on operating time.

The SEC system is partially described in references 7 and 8 . The SEC includes gloveboxes and their controls, and secondary piping around the process piping. The system houses nearly all tritium-bearing components at TSTA. The system serves as an additional tritium confinement barrier in case process piping is somehow breached. The SEC provides continuous confinement and monitoring to the tritium piping, and it functions independent of TSTA main flow loop operation. The only times SEC components are out of service are when there are maintenance sessions on the gloveboxes themselves or on system components within the gloveboxes. Such 'in glovebox' maintenance occurs with a rough frequency of $0.5 /$ year per glovebox, as estimated from the past three years of TSTA operations. Maintenance performed on the gloveboxes is all manual, but most maintenance is performed while the glovebox is operating, for example, leak testing and detector calibration. The only glovebox maintenance activities that require glovebox shutdown are window seal changeout, nitrogen valve repair or replacement, passbox maintenance, or perhaps glove changeout.

Table 1 gives the names, locations, and ages of the TSTA gloveboxes. The following paragraphs describe the gloveboxes, pressure control systems, monitors, system interfaces, and interbox piping at TSTA.

\section{Glovebox units}

The glovebox bodies are built of 6061 aluminum $(4.8-\mathrm{mm}$ thick) or 316 stainless steel (2.8-mm thick), with clear polycarbonate (lexan, 6.4-mm thick) windows. The bodies are all welded construction. Aluminum is 
TABLE 1. TSTA GLOVEBOX DESCRIPTIONS

\begin{tabular}{|c|c|c|c|c|c|}
\hline & & Age & & Volume & No. of \\
\hline Glovebox Name, Abbreviation & Location & (yrs) & Materials & $(\mathrm{m} 3)$ & Gloves \\
\hline $\begin{array}{l}\text { Experiments \#2 } \\
\text { (Raman Spectroscopy), EXP2 }\end{array}$ & mezzanine & 1 & $\begin{array}{l}\text { steel, } \\
\text { hypalon }\end{array}$ & 1.7 & 8 \\
\hline $\begin{array}{l}\text { Tritium Load In/Load Out } \\
\text { station, LIO }\end{array}$ & main floor & 1 & $\begin{array}{l}\text { aluminum, } \\
\text { hypalon }\end{array}$ & 0.8 & 8 \\
\hline Experiments \#1, EXP1 & mezzanine & 2 & $\begin{array}{l}\text { aluminum, } \\
\text { hypalonb }\end{array}$ & 1.7 & 4 \\
\hline Gas Analysis Lab, GAN & experiment room & 3 & $\begin{array}{l}\text { steel, } \\
\text { hypalon }\end{array}$ & 1.7 & 8 \\
\hline $\begin{array}{l}\text { Japanese Fuel Cleanup } \\
\text { Unit, JFCU }\end{array}$ & main floor & 2 & $\begin{array}{l}\text { steel, } \\
\text { buty }{ }^{c}\end{array}$ & 13 & 52 \\
\hline $\begin{array}{l}\text { Experimental Contamination } \\
\text { Studies \#2, XCS2 }\end{array}$ & experiment room & 7 & $\begin{array}{l}\text { steel } \\
\text { hypalon }\end{array}$ & 1.3 & 12 \\
\hline Inventory box, INV & $\begin{array}{l}\text { removed, } 11 / 91 \\
\text { replaced by LIO }\end{array}$ & 7 & $\begin{array}{l}\text { steel } \\
\text { hypalon }\end{array}$ & 2.3 & 6 \\
\hline $\begin{array}{l}\text { Experimental Contamination } \\
\text { Studies } \# 1 \text {, XCS1 }\end{array}$ & $\begin{array}{l}\text { experiment room } \\
\text { (never used) }\end{array}$ & 0 & $\begin{array}{l}\text { aluminum, } \\
\text { hypalon }\end{array}$ & 1.7 & 4 \\
\hline Fuel Cleanup, FCU & pit & 8 & $\begin{array}{l}\text { aluminum, } \\
\text { hypalon }\end{array}$ & 4.6 & 20 \\
\hline Uranium Tritide Beds, UTB & pit & 8 & $\begin{array}{l}\text { aluminum, } \\
\text { hypalon }\end{array}$ & 2.9 & 12 \\
\hline $\begin{array}{l}\text { Isotope Separation Systein } \\
\text { unit \#1, ISSI }\end{array}$ & mezzanine & 8 & $\begin{array}{l}\text { aluminum, } \\
\text { hypalon }\end{array}$ & 1.2 & 6 \\
\hline
\end{tabular}


TABLE 1. TSTA CLOVEBOX DESCRIPTIONS (cont inued)

\begin{tabular}{|c|c|c|c|c|c|}
\hline & \multicolumn{3}{|c|}{ Age } & \multirow{2}{*}{$\begin{array}{l}\text { Volume } \\
\text { (m3) } \\
\end{array}$} & \multirow{2}{*}{$\begin{array}{l}\text { No. of } \\
\text { Gloves }\end{array}$} \\
\hline Glovebox Name, Abbreviation & Location & (yrs) & Materials & & \\
\hline $\begin{array}{l}\text { Isotope Separation System } \\
\text { unit \#2, ISS2 (or ISS/GAN) }\end{array}$ & mezzanine & 8 & $\begin{array}{l}\text { steel, } \\
\text { hypalon }\end{array}$ & 1.3 & 4 \\
\hline $\begin{array}{l}\text { Transfer Pumping } 1 \text { and } 2 \text {, } \\
\text { TP1 }\end{array}$ & main floor & 8 & $\begin{array}{l}\text { a) uminum, } \\
\text { hypal on b }\end{array}$ & 2.5 & 12 \\
\hline Transfer Pumping 3, TP3 & pit & 8 & $\begin{array}{l}\text { a) uminum, } \\
\text { hypalonb }\end{array}$ & 3.4 & 8 \\
\hline Solid Waste Disposal, SWD & main floor & 8 & $\begin{array}{l}\text { a) uminum, } \\
\text { hypalon b }\end{array}$ & 3.6 & 16 \\
\hline TOTALS & & \multicolumn{2}{|c|}{$\begin{array}{l}79 \text { glovebox-years, } \\
\text { ages rounded down } \\
\text { to nearest full yr }\end{array}$} & \multicolumn{2}{|c|}{$\begin{array}{l}176 \text { gloves } \\
\text { in use }\end{array}$} \\
\hline \multicolumn{6}{|c|}{$\begin{array}{l}\text { Remark: A1l gloveboxes at TSTA have lexan windows } \\
\text { Note a. } 316 \text { stainless steel frame, lexan windows, hypalon rubber gloves } \\
\text { Note b. } 6061 \text { aluminum frame, lexan windows, hypalon rubber gloves } \\
\text { Note c. } 316 \text { stainless steel frame, lexan windows, butyl rubber gloves }\end{array}$} \\
\hline
\end{tabular}


preferred for future glovebox acquisitions because it has several advantages over stainless steel, such as: lesser cost, lighter weight, easier machining for potential modifications, better weldability, no nickel present to catalyze HT to HTO conversion, and easier decontamination after tritium exposure. ${ }^{9}$ The TSTA data does not show a failure rate advantage to either material. Figure 1 gives a sketch of the basic glovebox unit. The lexar, windows are each typically $1.1 \mathrm{~m}$ wide by $0.8 \mathrm{~m} \mathrm{high}$, and employ $663.2-\mathrm{mm}$ bolts to mount the window to a glovebox body. The bolt heads are epoxied to the interior of the glovebox body for leak tightness, and ease of window removal and replacement operations. The bolt threads extend through the glovebox body, a rubber seal, the lexan window, and an aluminum window frame before a nut is applied to torque down the bolt. The aluminum frame is about $32-\mathrm{mm}$ by $4.8-\mathrm{mm}$ in cross section, and it is rectangularly shaped to fit around the $1.1 \mathrm{~m}$ by $0.8 \mathrm{~m}$ perimeter of the lexan window. The window frame distributes the bolt load stresses evenly across the edge of the ivindow. The windows typically have a $10^{\circ}$ slope from vertical to better accommodate ergonomic factors in glove work. The Japanese Fuel Cleanup Unit (JFCU), experimental contamination studies \#2 (XCS2), and isotope separation system \#1 (ISS1) gloveboxes do not have sloped windows.

These glovebox bodies have many penetrations for electrical power feedthroughs to motor operated valves, control wiring, instrument taps, gas piping into and out of the box, etc. There are on the order of perhaps 50 penetrations for a typical glovebox. These are all leak checked each year. The leakage criteria are that a glovebox is considered to be acceptable when no leak can be found with a helium leak detector that detects to $3 E-10$ standard $c c / s e c o n d$ while the glovebox is pressurized to about $+2 \mathrm{kPa} .{ }^{9}$ While a large number of penetrations means that there is more chance of leakage, the large number also means that there is a high degree of flexibility in glovebox operations at TSTA.

The glovebox units are mounted on steel stands about $1-m$ high. The stands are anchored to the concrete floor, and are able to withstand seismic events up to 0.33 gravity lateral acceleration.

One operational addition at TSTA has been to place a telltale marker 

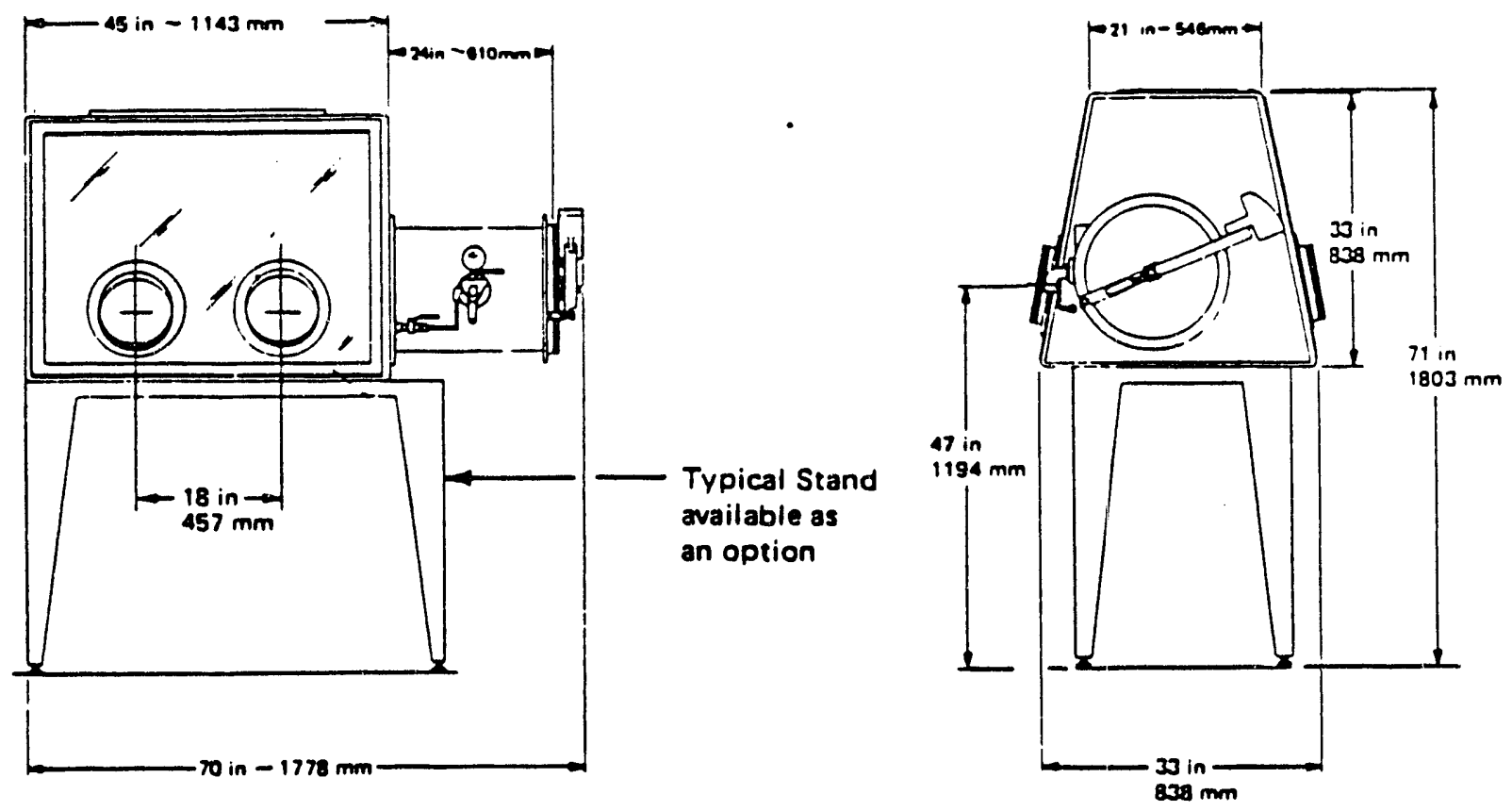

figure taken from Vacuum/Atmospheres Company catalog

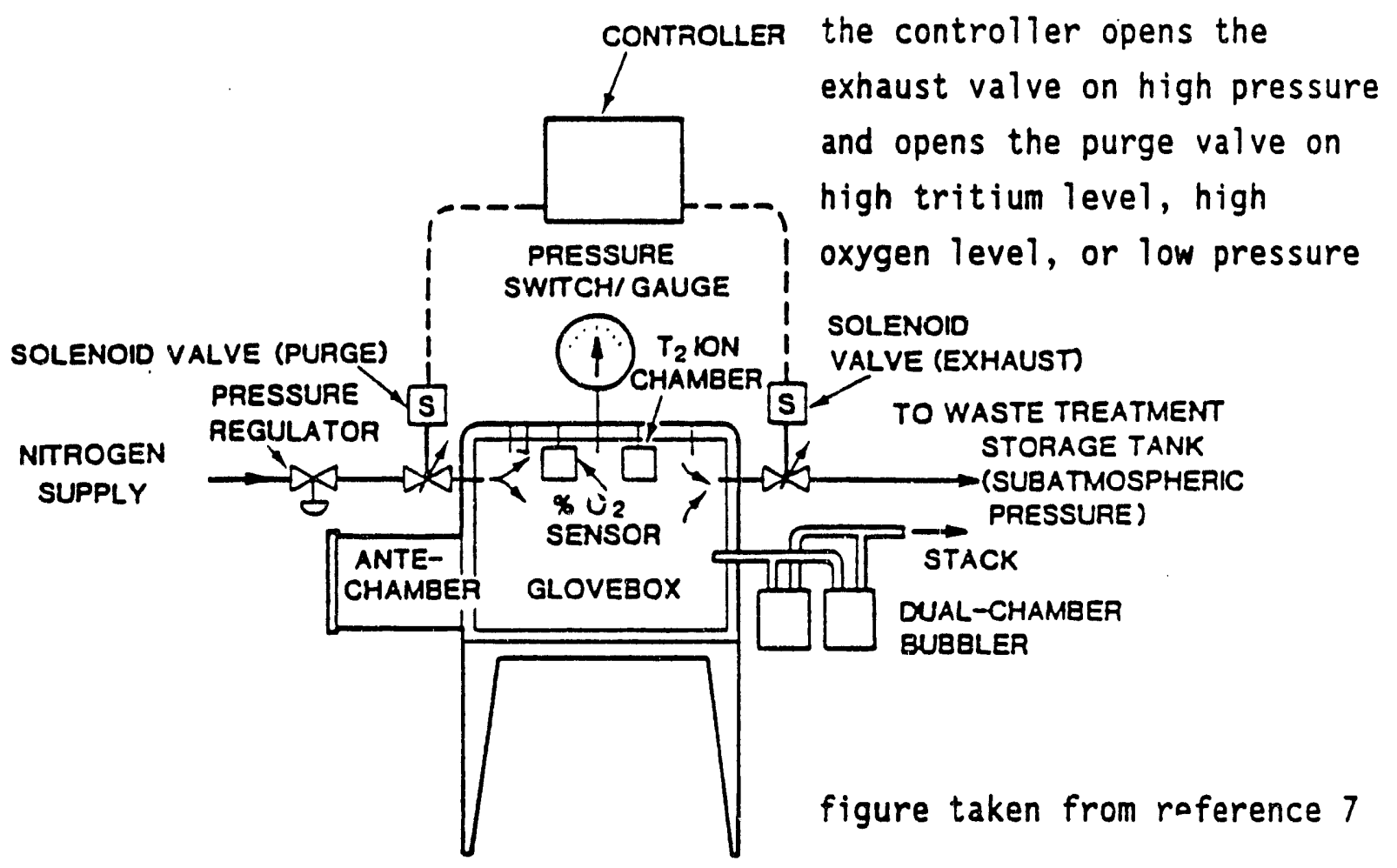

Figure 1. Glovebox sketches. 
(a small dab of red plastic liquid that quickly solidifies) on the exterior thieads of assembled window bolts that have passed leak checking. If the bolt is tightened, loosened, or disturbed for any reason, the telltale marker will also be disturbed, and leak checking teams must revisit that particular boilt.

\section{Glovebox gloves}

Gloves are made of hypalon rubber (chlorosulfonated polyethylene), usually $0.76-\mathrm{mm}$ thick and $0.76 \mathrm{~m}$ in length. The glove ports are aluminum, of a standard $200-\mathrm{mm}$ diameter, usually $457 \mathrm{~mm}$ on center between ports. However, these dimensions can and do vary with the application of the particular glovebox and the equipment to be handled inside the glovebox. The experiments \#1 glovebox has 4 gloves that are thinner than normal, only $0.4-\mathrm{mm}$ thick, to allow for more sensitive handling of the experiment equipment housed inside it. The JFCU glovebox gloves are made of butyl rubber, and are $0.5-\mathrm{mm}$ thick. All gloves are fastened to aluminum glove ports using worm screw-type steel band clamps recessed in grooves in the cylindrical glove port. These clamps are inexpensive and provide good compression for minimal torque on the screw. The glove ports themselves are each held in place by six bolts to the glove port interior fitting. The gloves are the molded left- and right-handed type, rather than ambidextrous. The effectiveness of left/right or ambidextrous gloves appears to be a matter of personal preference. The gloves do seem to be somewhat easier to use in slightly subatmospheric pressure gloveboxes that the past slightly overpressire gloveboxes.

\section{Glovebox window seal}

The lexan window seals for the gloveboxes are flat butyl rubber gaskets, 6.4-mm thick and 25.4-mm wide. They are placed around the perimeter of the window, with holes to allow the rubber seal to fit around the window's bolts.

\section{Glovebox overpressure protection}

All of the TSTA gloveboxes are fitted with a bubbler liquid seal pressure relief system. Figure 2 gives a diagram of the bubbler system. 


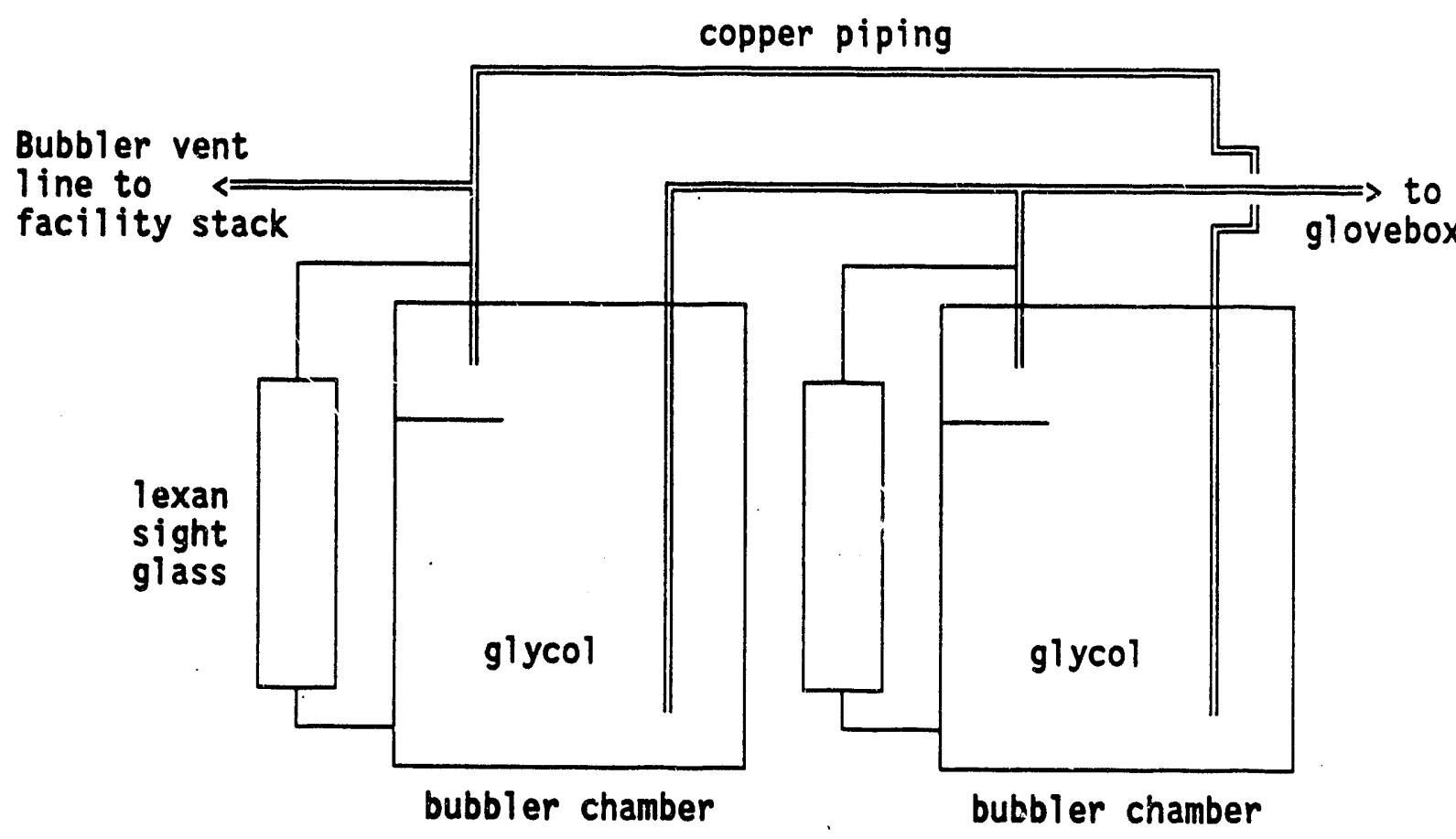

Figure 2. Double acting, liquid seal bubbler system for TSTA gloveboxes. 
Each bubbler is a two stainless steel chamber unit, each chamber measuring $154-\mathrm{mm}$ high and $127 \mathrm{~mm}$ in diameter. One chamber is connected to a $32-\mathrm{mm}$ diameter copper exhaust line to the facility vent stack and the other chamber is connected to a $32-\mathrm{mm}$ diameter port in the glovebox metal wall. Bubbler chambers are interconnected with $25-\mathrm{mm}$ diameter copper pipe to create a liquid level pressure balance between the glovebox nitrogen atmosphere and the vent stack line. The bubbler liquid is ethylene glycol, chosen because of its low viscosity and its resistance to evaporation (it will; however, uptake some tritium). Low viscosity $0 i 1$ could also be used. Each bubbler chamber contains about a liter of glycol. A lexan sight glass is provided on each chamber to show the bubbler's glycol level, and each sight glass is checked at least monthly. The bubbler controls nitrogen pressure in the glovebox so that vent stack nitrogen/air is drawn into the glovebox when glovebox pressure falls to less than $1 \pm 0.25 \mathrm{kPa}$ below the glovebox's operating pressure, and the bubbler allows exhaust of glovebox overpressure to the stack when the nitrogen pressure exceeds $1 \pm 0.25 \mathrm{kPa}$ above operating pressure. We note that any atmospheric pressure changes, wind loads at the 30 -m stack, etc., would have to be quite extreme to affect the double-acting bubblers. The bubblers function to keep glovebox pressure well within the manufacturer's suggested range of $\pm 2.5 \mathrm{kPa}$ around atmospheric pressure (note: at TSTA's altitude, $2.2 \mathrm{~km}$ above sea level, atmospheric pressure is about $78.6 \mathrm{kPa}$ or 590 Torr). The bubbler minimum flow rate is about 301 iters/s at \pm 2 $\mathrm{kPa}$. Glovebox pressurized leak testing is performed at about 600 to 625 $\mathrm{Pa}$ above glovebox operating pressure, but still below the pressure required for the bubbler to begin operating.

An early bubbler problem was the suction of tritium contaminated fluid back into the gloveboxes. ${ }^{7}$ This problem created high tritium readings and consequently, continuous purging that wasted nitrogen. Another concern was the contamination of glovebox components that might need later maintenance. The prolllem was solved by placing baffle plates under the shorter bubbler ports, as shown in Figure $2 .^{7}$

If the glovebox tritium monitor senses tritium inside the glovebox, the purge valve will open. As pressure increases, the exhaust valve will open and reclose in cycles to route the tritiated gas to the TWT. It is 
possible that a glovebox could overpressurize enough, or the bubbler fluid be low enough, to cause the bubbler to allow tritiated gas to be routed to the vent line to the stack. The vent line at the stack is continuously monitored for tritium, and the monitors would close valves in the vent lines and shut down ventilation system blowers on detecting a large amount of tritium, over $10 \mathrm{millicuries} / \mathrm{m}^{3}$.

\section{Glovebox nitrogen supply}

Nitrogen gas is routed to the gloveboxes from the TSTA nitrogen supply system. Originally, the supply system was a commercial 'tube trailer' unit of pressurized nitrogen cylinders. In 1989, this system was converted to use a liquid nitrogen and heat exchanger technique to generate nitrogen gas. The new system provides a larger reserve supply of about $140-\mathrm{kPa}$ gaseous nitrogen. There are one or two liquid nitrogen deliveries per week, to supply a use of about $2.3 \mathrm{~m}^{3}$ of liquid nitrogen each week. The gloveboxes are responsible for over $95 \%$ of the total nitrogen usage at TSTA. Other uses include nitrogen operated valve cycling, molecular sieve bed regeneration, etc. The new nitrogen supply system reduces the possibility of running out of nitrogen because of errors in switching tube trailer cylinders (see report 374 in Appendix B).

\section{Glovebox passboxes}

Most of the gloveboxes at TSTA have airlock type passboxes (antechambers) connected to them for loading equipment in and out of the gloveboxes. The ISS2 glovebox does not have a passbox, and the GAN glovebox has a large passbox. The passboxes are cylindrical, constructed of the same materials as the parent glovebox, and they have latching doors at each end. The passboxes are plumbed to house vacuum lines to evacuate air from the box, to nitrogen supply lines to fill the box with dry nitrogen gas, and a vent stopcock to equalize pressure for opening the exterior door. Most passboxes are $380 \mathrm{~mm}$ in diameter and $610 \mathrm{~mm}$ in length, although the large GAN passbox is $559 \mathrm{~mm}$ in diameter and $710 \mathrm{~mm}$ in length. The typical operating procedure is to keep the passbox doors shut with a low pressure nitrogen cover gas inside the box. Pressure adjustments must be made to be able to open the door to the atmosphere. 
One operations difficulty was tritium contaminated vacuum pump oil streaming back into the passboxes. This problem was solved by installing an oilless scroll pump for the house vacuum system. ${ }^{\text {? }}$

One glovebox, the XCS2 glovebox, has a single latch mechanism door on the side, rather than a passbox. At one time, the box had an airlock, but it was removed to allow personnel access into the rest of the experiment room XCS2 resides in. The door is referred to as a 'refrigerator style' door because of the type of latch and the appearance of the door seal material. This door has caused problems with tritium leakage outward and, later, air leakage inward. Use of this glovebox was suspended at the end of 1990. It was decommissioned and decontaminated by TSTA operators at the end of 1991 .

\section{Glovebox nitrogen pressure control}

The nitrogen gas flow to the gloveboxes is controlled by valve controllers that operate $6.4-\mathrm{mm}$ diameter supply and exhaust brass solenoid valves. The purge nitrogen sweeps the gloveboxes when radiation levels reach instrument setpoints ( $\left.1 \mathrm{millicurie} / \mathrm{m}^{3}\right)$, glovebox pressure climbs from air inleakage (or lowers due to vacuum system leaks inside the box), or the oxygen concentration reads high (greater than $2 \%$ ). The normal purge flow rate is about 0.5 to 0.8 liter of nitrogen/s. A rough rule of thumb for TSTA gloveboxes is that about an hour is needed per cubic meter of glovebox volume to purge out small in-glovebox tritium releases, to be cleaned up by the Tritium Waste Treatment System (TWT). About 24 hours is needed to completely purge the largest of the TSTA system gloveboxes after they have been opened up to air. The larger JFCU glovebox takes somewhat longer. Detritiated nitrogen purge gas from the TWT output is vented from the $30 \mathrm{~m}$ high facility vent stack. Nitrogen is used because it is inexpensive and more readily available than argon or helium, and it is compatible with nitrogen-operated valves that exhaust into the gloveboxes. The nitrogen is not recycled from the TWT to SEC because, if the TWT became degraded (inefficient) and did not remove all of the tritium, then all of the gloveboxes would become contaminated from the remaining tritium entrained in the recycled gas. 
Originally, the gloveboxes were operated at static (atmospheric) to slightly above atmospheric pressure (about $500 \mathrm{~Pa}$ above). This initial operating strategy was adopted for two reasons. First, there was a siafety concern over the presence of oxygen from air intrusion into a glovebox. oxygen in the glovebox would allow tritium conversion to tritiated water, which is biologically more hazardous, it would threaten a hydrogen explosion, and could also threaten a uranium pyrophoric reaction in the uranium storage beds. The other reason was that the original set of pressure controllers were considered to be more reliable (have fewer demands) operating at static to s?ightly above atmospheric pressure than at static to slightly below atmospheric pressure.

In June of 1991, the operating philosophy changed to operate the gloveboxes at static to $500 \mathrm{~Pa}$ below atmospheric pressure. Since the overpressure relief bubblers are double acting, there was no difficulty in making this change. The reason for this change was to eliminate the possibility of a tritium leak out into the TSTA main cell room. This change was implemented about three months after the event discussed in failure report 503 (see Appendix B). The gloveboxes, which were being thoroughly leak checked at the beginning of 1991, were carefully leak checked again and were leak tightened again, so that air inleakage would be reduced to very low levels. The additional glovebox leak tightening also helped reduce the number of demands on the pressure control system. Mr. J. Miller of TSTA estimated that purge and exhaust valve cycling demands were reduced by at least a factor of five, and perhaps as much as a factor of eight, after the gloveboxes were thoroughly leak tightened. ${ }^{10}$

The original pressure control system was a photohelic pressure controller with adjustable setpoints for the operating pressure band. A diaphragm was used to sense the change in pressure between room air and the glovebox. The diaphragm worked well, but the system components to - actuate the nitrogen supply and exhaust solenoid valves did not. The system worked in the following manner. Diaphragm movement caused an indicator needle to move. As light from the small bulb attached to the indicator needle came close to a pressure controller setpoint light receptor, the light would cause a photohelic relay to close, thereby 
actuating control current for a mechanical relay that controlled 120 Volt line power to the solenoid valve. The photohelic relays did not draw much current, but would build up resistance on the contacts and would begin sticking in position. This would cause the mechanical relay to remain closed, thereby keeping the respective solenoid valve open. ${ }^{10}$ often, operators would simply tap the face of the controller to vibrate the photohelic relays loose. This solution to valve sticking was often written in the immediate corrective action portion of the failure reports. The photohelic system was reasonably inexpensive to purchase, and the manufacturer believed that the only limitation was the lifetime of the fine filament bulb attached to the indicator needle. Unfortunately, these pressure controllers did not function well and were a continual source of problems for the operations staff at TSTA. The majority of reports in Appendix $B$ are underpressure and overpressure events caused by these controllers.

The pressure controller problem was recognized after the first few years of TSTA 1 ife, as the units began to malfunction on a periodic rather than random basis. This problem is not unique to TSTA. At least one other case of inadequate glovebox pressure control at a tritium facil ty has been recently reported. 11 At TSTA, alternative means of pressure control were sought. For a brief time, pressure switches were used in several of the gloveboxes, for acceptability testing. Pressure switches also use a diaphragm to compare room air pressure to glovebox pressure. The diaphragm is designed to press against a mechanical linkage, to convert pressure energy into mechanical energy, thus closing electrical contacts to the relay controlling the solenoid valve power. The pressure switches were inexpensive, but the contacts of these also tended to stick closed after repeated cycling. Since the units were easily replaced, there was no detailed investigation of the cause for these contacts sticking. The pressure switches were abandoned as a non-viable solution, and the photohelic relay pressure controllers were user again while other means of pressure control were sought.

In mid-1991, conversion of all gloveboxes to new solid state gauge pressure transducers was completed at TSTA. The pressure transducer converts pressure energy into an electrical energy signal using 
piezoelectric quartz crystals, then an electronic circuit measures the voltage of the electrical signal. Based on the measurement and its comparison to preselected pressure (voltage) settings, the device either sends a signal to open the appropriate solenoid valve, or waits.for a larger change in voltage. A time delay relay will close the valve within a typical 5 seconds (this time is variable on the local control circuit board). The pressure evaluation process is continual.

This new pressure transducer system has worked well in most of the gloveboxes for the first year of operation, and since the technology behind these pressure transducers and the other solid state components in the new system is well established, the TSTA staff has an optimistic outlook for the reliability of the new pressure control system. This pressure control technology is only perhaps three years old, although all of the individual components have been used in other sorts of applications for a much longer time. ${ }^{10}$ Unfortunately, there is not enough operating time built up with the new system to accurately assess its service reliability. The JFCU glovebox did experience a failure of the neis vacuum measurement gauje, but this was found to be a factory defect. In January 1990, the JFCU unit experienced inleakage water from the humidity collected on the adjacent oxygen monitor (the JFCU entered service with this new system in place). The manufacturer fixed the inleakage problem, and the unit has run flawlessly since then.

To illustrate this point of insufficient service life to properly estimate reliability, we count the one failure event over an estimated one year of operation with 14 gloveboxes. Estimated failure rates for the new pressure control system would be on the order of 0.07 failures per glovebox-year, with a $95 \%$ upper bound of roughly $0.4 /$ glovebox-year. While this point estimate is roughly a factor of 8 lower than the failure rates for the old pressure control system, there is a reasonable anticipation that the new system failure rate could be much lower with longer operating time.

The failure rate calculations presented later in this report will treat the older pressure control system, since there is not enough time accumulated on the new system to accurately assess its reliability. If 
reliability estimates are needed for the new system, fault trees should be constructed and quantified with solid state component failura rates taken from established literature sources. Using these established data sources will provide good reliability estimates for the mature technology utilized in the new pressure control system.

\section{Oxygen monitors}

Each glovebox has a dedicated oxygen monitor that continuously reads the percent of oxygen in the glovebox and reports this information to the Master Data Acquisition Computer. Oxygen concentrations greater than $2 \%$ will cause an alarm readout in the control room, and the computer will automatically begin purging the glovebox with nitrogen, routing any glovebox effluent gas to the TWT. For low inventory gloveboxes (LIO, TPI, TP3, experiments, etc., contain less than 1 gram of tritium), there is no significant explosive threat from oxygen inleakage. We note that in the case of a pressure reverse that forces the bubbler to lose its glycol into a glovebox, air from the stack vent line can flood into the gloveboxes. Air, at $21 \%$ oxygen, in the high inventory gloveboxes (UTB can hold up to 150 grams of tritium), could pose an explosive threat. The glovebox oxygen monitors are inspected and recalibrated every twelve months, and the detector cell electrolyte is also replenished during those maintenance sessions. The original oxygen monitors were replaced in the mid-1989 time frame.

The original oxygen monitors analyzed roughly $1,000 \mathrm{cc} /$ minute, gave a response in less than one minute, and were accurate to \pm 1 part per million. They compared the glovebox atmosphere sample with a reference gas cartridge that has a nitrogen/hydrogen gas mixture (and zero oxygen gas) held inside. The unit consisted of a small diaphragm pump to move the glovebox gas through the analyzer, a detector cell, a meter readout, a sight glass for gas flow visual reference, and the control panel circuitry to transmit an alarm if the oxygen concentration was too high. The glovebox gas samples used for analysis was returned to the glovebox.

The new oxygen monitors work on a different principle, and are believed to be somewhat more reliable than the predecessors. The glovebox 
atmosphere is sampled by diffusion through a diffusion barrier. Any oxygen passing through the barrier is electrochemically reduced to hydroxyl ions in a reaction at a cathode. Then, an electrolyte solution of potassium hydroxide assists the hydroxyl ions to migrate to an anode, where they reform elemental oxygen. A direct current voltage of 1.3 Volts provides the driving force for these two chemical reactions. The resulting electrical current to the anode is directly proportional to the oxygen concentration in the gas stream. This electrical current is translated to oxygen concentration on a panel meter. The gas samples are then routed to the TWT for processing.

\section{Interbox piping}

The TSTA process lines are copper, $6.4-\mathrm{mm}$ in diameter, and can carry up to 1 kilogram of tritium per day. The secondary containment piping lines can be al uminum pipe, $32-\mathrm{mm}$ in diameter, or flexible plastic pipe with a helical spring wrap for stability, or polyvinyl chloride (PVC) rigid plastic pipe. The primary piping is axially centered in the secondary piping by periodically placed disks that keep the primary pipe centered. One end of each secondary piping run is connected to one glovebox for nitrogen purge, and the other end is blanked off at the penetration to the second glovebox. This design feature prevents any spread of contamination between gloveboxes. The interbox piping is vacuum tight, and uses fittings. The annular space between primary and secondary pipes is kept at the same nitrogen pressure as the gloveboxes. There is on the order of $200 \mathrm{~m}$ of interbox piping at TSTA. This piping has enough flexible sections included to allow it to withstand 0.33 gravity lateral ground acceleration from an earthquake event.

\section{Tritium Waste Treatment System}

The Tritium Waste Treatment System (TWT) accepts purged nitrogen gas from the gloveboxes. The gas accumulates in a large tank, the low pressure receiver, which is held at subatmospheric pressure. The tank is sized to accommodate simultaneous flow from all TSTA gloveboxes, about $30 \mathrm{~m}^{3} /$ hour. However, this situation is rare, and typical nitrogen flow rates are on the order of perhaps 10 to $15 \mathrm{~m}^{3} /$ hour. Pressure control 
problems can lead to excessive nitrogen consumption, but an average facility usage is $2.2 \mathrm{~m}^{3}$ of liquid nitrogen each week. The TWT processes gaseous nitrogen to remove tritium and vents the clean nitrogen out the $30-\mathrm{m}$ high facility vent stack. Information on reliability of TSTA's TWT system is found in reference 12 . 


\section{SECONDARY CONTAINMENT SYSTEM FAILURE DATA ANALYSIS}

This section describes the failure data analysis and failure rate calculations for the glovebox system. Appendix A gives some representative failure rate calculations. Table 1 in the previous section gave the constivative number of operating years for each of the TSTA glovebox units. Counts of number of gloves in use and total time of glove use were also given in that table. Since the count of glovebox components and the total time of operation are known, attention is focused on the failure reports. These reports are summarized in Appendix $B$, so only report numbers and counts of similar events are discussed in this section.

The glovebox failure modes, that is, ways that the glovebox can fail, are limited. A good description of glovebox safety and failure modes is given in reference 13 . The failure modes of relevance for most glovebox operations are:

Fire inside glovebox

Explosion inside glovebox

Excessive pressurization inside glovebox (overpressure)

Excessive negative pressure inside glovebox (underpressure, air inleak) Glove breach failures

Transfer system (passbox) breach failures

Since TSTA has never had a fire or explosion inside a glovebox over the eight years of operations there, a $50 \%$ Chi-square distribution for zero failures gives us $(0.455) /(2 \times 79$ glovebox-years $)=0.003 /$ glovebox-year point estimate for fires or explosions. However, I expect that tritium glovebox fires and explosions should have frequencies lower than $0.003 / \mathrm{glovebox}-y r$. This TSTA value should be considered as an upper bound, because longer operating times will certainly give lower frequency values.

r.lovebox fires have been a significant safety hazard when the glovebox itself is the primary confinement for a inert cover gas over pyrophoric materials, like plutonium ur uranium. For example, the Rocky Flats weapons production plant has dealt extensively with plutonium, and has had several glovebox fires in its approximately 40 -yr lifetime. ${ }^{14}$ 
TSTA is very different from Rocky Flats. For a glovebox fire or explosion to occur at TSTA, multiple barriers must be breached. A significant quantity of tritium, hydrogen, or some combustible material must leak out of process piping into a glovebox without detection from the process system or the glovebox tritium munitor, then significant air must leak into the glovebox without detection by the oxygen monitor (and subsequent mitigation), then the mixture must be ignited by some means. The only pyrophoric material at TSTA, the storage bed uranium, is doubly confined under nitrogen gas to prevent any air admission. TSTA takes these precautions and uses the monitors to preclude such events. Assuming that 3E-03/glovebox-year is an upper bound is safety conservative.

This data anaiysis will deal with the glovebox failure modes of overpressure, underpressure, air leakage, and small tritium release events. We also consider other failure modes, such as continuous purging, that have occurred during TSTA operations. Glove failures will be treated, but passbox failures have not occurred, and since the passboxes are not used very frequently, they will not be treated. Table 2 gives the information of which failure report numbers describe the different failure modes for the TSTA gloveboxes. These reports span the time frame of interest, 1984 to 1991.

Table 3 gives the failure report numbers categorized by the failed component. From these data, along with the fact that the gloveboxes are continuously in use, failure rates are calculated. Details of failure rate calculations are given in Appendix $A$. The failure rates presented here use 79 glovebox-years of operation, as cited in Table 1. From Table 3 , we have 26 events of glovebox overpressure (not so severe as to cause a breach to the room), 15 events of glovebox underpressure, 3 events of unneeded continuous purging, 2 events of air inleakage (over only about 1 year of TSTA operation at negative pressure), 1 fault of the new pressure control system over roughly one year of operation, and 3 small tritium release events. There were no passbox failures reported in the time period under study. Glove breach events are treated later in this section.

Table 4 gives the failure rates for various SEC glovebox failure 
TABLE 2. TSTA GLOVEBOX FAILURE REPORT IDENTIFICATION NUMBERS BY GLOVEBOX AND FAILURE MODE

\begin{tabular}{|c|c|c|c|c|c|c|}
\hline \multirow{2}{*}{\multicolumn{2}{|c|}{ Glovebox }} & \multicolumn{5}{|c|}{ Failure Report Identification Numbers by Failure Modes } \\
\hline & & & & Continuous & Air & Tritium \\
\hline \multicolumn{2}{|c|}{ Identifier } & Overpressure & Underpressure & Purge & Inleak & release \\
\hline \multicolumn{2}{|c|}{ EXP2 } & - & - & 411 & - & - \\
\hline \multicolumn{2}{|l|}{ LIO } & - & - & - & - & 503 \\
\hline \multicolumn{2}{|l|}{ EXP1 } & - & - & - & - & - \\
\hline \multicolumn{2}{|l|}{ GAN } & - & $343,396,414,454$ & - & - & - \\
\hline \multicolumn{2}{|l|}{ JFCU } & 509 & - & - & - & - \\
\hline \multicolumn{2}{|l|}{$x \operatorname{cs} 2$} & 455 & - & - & 520 & 249 \\
\hline INV & 10 & $7,319,352,397$ & $114,163,384,398$ & - & - & 212 \\
\hline$x \operatorname{CS} 1$ & & Thi & s glovebox was $n$ & ver operated & & \\
\hline FCU & & 210 & - & - & - & - \\
\hline UTB & & $2,476,485$ & - & - & - & - \\
\hline ISSI & & $0,412,456,463$ & 494 & 255 & 513 & - \\
\hline ISS/GAN & & $3,437,491$ & 050,113 & - & - & - \\
\hline $\mathrm{TP1}$ & & $0,294,373$ & - & 293 & - & - \\
\hline TP3 & $04 !$ & & 265,279 & $\therefore$ & - & - \\
\hline SWD & $\begin{array}{l}107 \\
496 \\
\end{array}$ & $\begin{array}{l}7,280,321,433, \\
6\end{array}$ & 112,278 & - & - & - \\
\hline \multicolumn{7}{|c|}{ Total Counts } \\
\hline \multicolumn{3}{|c|}{ of TSTA Events: 26} & 15 & 3 & 2 & 3 \\
\hline
\end{tabular}


IABLE 3. TSTA GLOVEBOX FAILURE REPORT IDENTIFICATION NUMBERS BY COMPONENT

Glovebox Failure Report Identification Numbers by Failed Component Type

Identifier Pressure Controller Supply Valve Exhaust Valve Other items

EXP2

LIO

EXP1

GAN

JFCU

XCS2

INV

$163,384,397$

411

$396,414,454$

509

455
FCU

UTB

ISS1

ISS/GAN

TP1

TP3

SWD
$050,413,437,491$

$052,476,485$

$255,412,456,463$

$293,294,373$

265

$112,278,321,433,496$

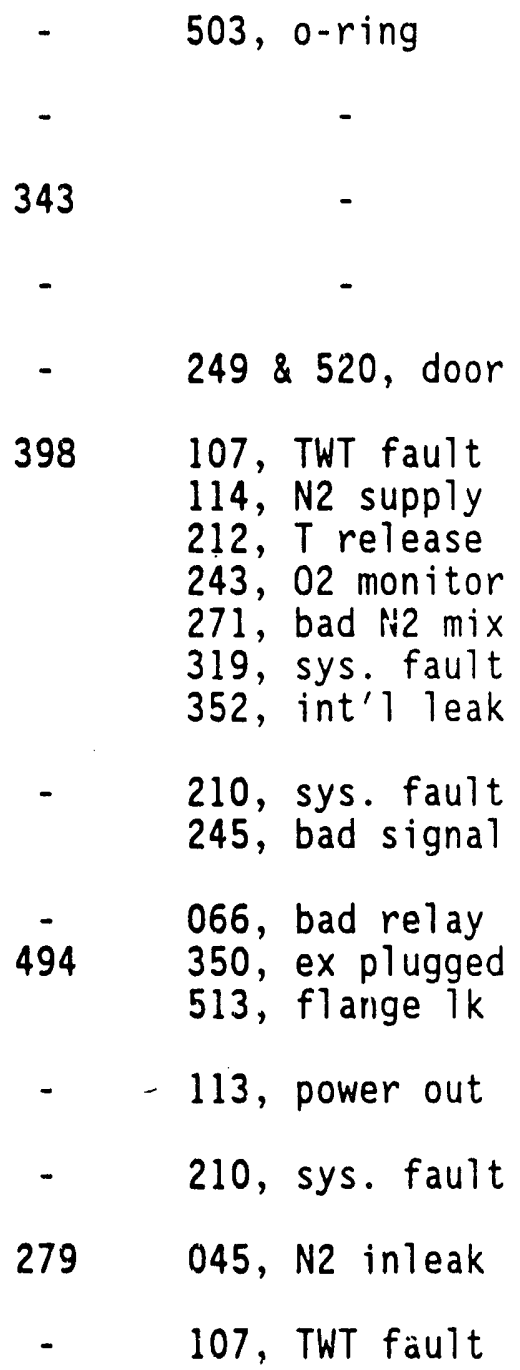

Report 259 was a pressure controller time delay relay failure, with unknown consequences. It was not counted. Report 426 described an unknown glovebox exhaust valve that stuck open. It was counted.

Note: Of the total of 63 reports dealing with gloveboxes or related sys tems, some reports were not significant. Reports 162, 166, 235, 237, $240,241.1,252,280,316,354$, and 374 were not used in this analys is because they either documented situations that were not failures, or did not pertain directly to the gloveboxes (nitrogen system, etc.). 
TABLE 4. TSTA GLOVEBOX AND GLOVEBOX COMPONENT FAILURE RATES

\begin{tabular}{|c|c|c|c|}
\hline \multicolumn{2}{|c|}{ Description of Failure Mode } & $\begin{array}{l}\text { Point Estimate } \\
\text { Failure Rate }\end{array}$ & $\begin{array}{l}95 \% \text { Upper Bound } \\
\text { Failure Rate }\end{array}$ \\
\hline \multicolumn{2}{|c|}{ Glovebox overpressure (a) } & $0.3 / g$ lovebox-year & $0.4 / g 1$ ovebox-year \\
\hline \multicolumn{2}{|c|}{ Glovebox underpressure (a) } & $0.2 /$ glovebox-year & $0.3 / g$ lovebox-year \\
\hline \multicolumn{2}{|c|}{ Glovebox continuous purging } & $0.04 /$ glovebox-year & $0.1 / g 1$ ovebox-year \\
\hline \multicolumn{2}{|c|}{$\begin{array}{l}\text { Air inleakage events } \\
\text { (one year of operation) }\end{array}$} & $0.1 / g$ lovebox-year & $0.5 / g$ lovebox-year \\
\hline \multicolumn{2}{|c|}{$\begin{array}{l}\text { Small, external tritium } \\
\text { release events to the room }\end{array}$} & $0.04 / g$ lovebox-year & $0.1 / g$ lovebox-year \\
\hline \multicolumn{2}{|c|}{$\begin{array}{l}\text { Solenoid valves, } \\
\text { fail to close on demand }\end{array}$} & $6 E-06 /$ demand & $3 E-05 /$ demand \\
\hline \multicolumn{2}{|c|}{$\begin{array}{l}\text { Oxygen monitor, } \\
\text { all failure modes }\end{array}$} & 3E-03/monitor-year & $2 E-02 /$ monitor-year \\
\hline \multicolumn{4}{|c|}{$\begin{array}{l}\text { (a) These values are for the older photohelic pressure control system. } \\
\text { The new system, in operation for about a year, already shows about } \\
\text { a factor of } 8 \text { improvement in reliability, and might show even more } \\
\text { in the future, over the photohelic system. } \\
\text { Note: Continuous purging could be the result of either the purge or the } \\
\text { exhaust valve being stuck open. Some TSTA gloveboxes will purge } \\
\text { continuously for valid reasons. This failure rate is for } \\
\text { inappropriate continual glovebox purging. } \\
\text { The operations staff admitted that the photohelic pressure control } \\
\text { system beinaved so badly that there were times that the gauge face } \\
\text { was tapped to arrest glovebox under- or over-pressure situations } \\
\text { and no failure report was filled out. The data results for the } \\
\text { pressure control system related failure modes should be considered } \\
\text { indicative of the order of magnitude of the true failure rate } \\
\text { rather than a finalized failure rate estimate. }\end{array}$} \\
\hline
\end{tabular}


modes. Glove failure rates are treated separately. It is important to note that as the problem with the pressure control system continued, the operators would not aiways file a failure report when they tapped the gauge face to vibrate the photohelic relay loose (so that the relay would change position) and end the overpressure or underpressure situation through proper supply or exhaust valve actuation.

Table 5 gives the citations of glove usage at TSTA. The numbers of glove replacements due to punctures, cuts or tears, pin hole leaks, wear on the glove port rims, etc., were found from the system operator's log book and from the cognizant operator, Ms. M. A. King. ${ }^{15}$ Glove failure rate comparisons to other operating experiences are discussed in the next section.

The point estimate failure rates and upper bound failure rates for standard $0.76-\mathrm{mm}$ thick hypalon gloves are given below:

Breach on rim $\quad 0.02 /$ glove-year, 95\% upper bound is $0.03 /$ glove-year Pin hole leak $\quad 0.01 /$ glove-year, $95 \%$ upper bound is $0.02 /$ glove-year Puncture $\quad 0.003 /$ glove-year, $95 \%$ upper bound is $0.008 /$ glove-year Abrasion wearout $0.009 / \mathrm{glove-jear,} 95 \%$ upper bound is $0.016 / \mathrm{glove-year}$ Cuts and tears $\quad 0.003 /$ glove-year, $95 \%$ upper bound is $0.008 /$ glove-year

Over eight years, these should be a rather complete set of types of glove failures experienced at TSTA. The overall failure rate for gloves can be obtained by adding all these point estimates together. The overall failure rate is about $0.05 /$ glove-year, with a $95 \%$ upper bound of $0.06 / g$ love-year.

The JFCU's 52 butyl gloves have been in use for two years. There have been two breaches, a tool puncture and a tear on a glove at its glove port rim. The point estimate failure rate (all failure modes) for these butyl gloves is 2 failures/( 2 years; $(52$ gloves $)=0.02 /$ glove-year, and the $95 \%$ upper bound would be about $0.06 / g$ love-year.

The solenoid valves have experienced four failures to close over the time period of this study. (report numbers 279, 343, 398, and 494). Discussions with Mr. J. Miller of TSTA indicate that there are two primary 
TABLE 5. TSTA GLOVE USAGE EXPERIENCE BETWEEN 1984 AND 1991

\begin{tabular}{|c|c|c|c|c|c|}
\hline $\begin{array}{l}\text { Glovebox } \\
\text { Descriptor }\end{array}$ & $\begin{array}{l}\text { Glovebox } \\
\text { Age (vrs) }\end{array}$ & $\begin{array}{l}\text { Number of } \\
\text { Gloves }\end{array}$ & $\begin{array}{l}\text { Type of } \\
\text { Gloves }\end{array}$ & $\begin{array}{l}\text { Thickness } \\
(\mathrm{mm})\end{array}$ & $\begin{array}{l}\text { Number of glove faults } \\
\text { requiring replacement }\end{array}$ \\
\hline EXP1 & 2 & 4 & hypalon & 0.4 & 1; failed on rim \\
\hline EXP2 & 1 & 12 & hypalon & 0.76 & 2 ; both pin hole leaks \\
\hline JFCU & 2 & 52 & butyl & 0.5 & $\begin{array}{l}\text { 2; } 1 \text { tool puncture, } \\
1 \text { small tear on rim }\end{array}$ \\
\hline GAN & 3 & 8 & hypalon & 0.76 & 0 \\
\hline LIO & 1 & 8 & hypalon & 0.76 & $\begin{array}{c}5 ; 4 \text { failed on rim, } \\
1 \text { pin hole leak }\end{array}$ \\
\hline FCU & 8 & 20 & hypalon & 0.76 & $\begin{array}{l}8 ; 6 \text { failed on rim, } \\
2 \text { pin hole leaks }\end{array}$ \\
\hline UTB & 8 & 12 & hypalon & 0.76 & $\begin{array}{c}4 ; 3 \text { failed on rim, } \\
1 \text { pin hole leak }\end{array}$ \\
\hline INV & 8 & 6 & hypalon & 0.76 & 0 \\
\hline ISS1 & 8 & 6 & hypalon & 0.76 & $\begin{aligned} 3 ; & 2 \text { failed on rim, } \\
& 1 \text { pin hole leak }\end{aligned}$ \\
\hline SWD & 8 & 16 & hypaton & 0.76 & $\begin{array}{l}\text { 7; damage to hands, } \\
\text { wearout abrasion }\end{array}$ \\
\hline TP1 & 8 & 12 & hypalon & 0.76 & $\begin{array}{l}4 ; 2 \text { failed on rim, } \\
1 \text { finger puncture, } \\
1 \text { cut in glove }\end{array}$ \\
\hline TP3 & 8 & 8 & hypalon & 0.76 & 1 ; a cut in glove \\
\hline$x C S$ & 0 & 4 & hypalon & 0.76 & 0 ; not used \\
\hline$x \operatorname{cs} 2$ & 7 & 12 & hypalon & 0.76 & 0 \\
\hline ISS2 & 8 & 4 & hypalon & 0.76 & $\begin{array}{l}2 ; 1 \text { impact puncture, } \\
1 \text { pin hole leak }\end{array}$ \\
\hline
\end{tabular}

Note: Total count of glove faults is 39 , rim failures, 18; pin hole leaks, 8 ; abrasion, 7 ; punctures, 3 ; cuts and tears, 3. 
causes for the valve failures. The first is foreign material (metal shavings or braze metal left in the pipes from construction, and dirt from the nitrogen supply system) in the nitrogen lines that causes binding and valve seat deterioration. The second cause is the light oil coating that the manufacturer puts on the valves. Over time, this coating dries and forms a dark powdery solid that binds up the solenoid plunger. 10

The typical number of demands for the solenoid inlet and exhaust valves is estimated at $1 E+04 /$ year. ${ }^{10}$ Considering that there are a total of $2(79)=158$ valve-years, then there have been about $1.58 E+06$ valve demands over the time period. An overall point estimate failure rate is 5 failures/1.58E+06 valve demands $=3 E-06 /$ demand. The $95 \%$ upper bound is $18.3 /(2)(1.58 E+06)$, or about $6 E-06 /$ demand. It is interesting to note that all of the reported valve failures are of the exhaust valves. These failures all occurred during the operations with slightly positive pressure on the gloveboxes. Considering just the exhaust valves, the failure rate becomes $5 /(79$ valve-years)( $1 E+04$ demands/year), or 6E-06/demand. A 95\% upper bound would be 3E-05/demand. The supply valves, with no failures, have a failure rate calculated from a $50 \%$ chi square distribution, or $(0.455) /(2)(79$ valve-years $)(1 E+04$ demands $/$ year $)=$ $3 E-07 /$ demand. Th: 1 is roughly a factor of 20 difference in the two failure rates.

The explanation for this failure rate variance is in the manner that the valves are operated. Purge (inlet) valves will open and remain open for high tritium or high oxygen signals, until the high level drops to an acceptable value. The exhaust valve must open and close periodically to maintain the correct pressure. When the exhaust valve opens, the pressure will decrease to below the preselected level, then the valve will close on its timer relay. With the purge valve remaining open, the exhaust valve is forced to continue exercising until the glovebox is restabilized at low tritium and/or oxygen levels. As stated previously, it can take hours to purge a glovebox, and up to 24 hours after it has been opened to air for maintenance. Conservatism suggests using the larger exhaust valve failure rate, rather than the overall valve failure rate, for future valve applications because it is a more accurate representation of the actual demands and failure experience of these purge and exhaust valves. 
Oxygen monitors for each of the gloveboxes appear to have worked well over the time period under study, but in this case, the data may not be accurate. One. report of a false high alarm in the INV glovebox, report number 243, July 1986, indicated that the oxygen monitors had some troublesome problems and that an individual unit had a mean lifetime of about 2 years. This 1 ife estimate is not consistent with the other recorded failure events, but the disprepancy could be due to misunderstandings in whose responsibility it was to fill out reports on oxygen monitor replacement. If we use the 2 year lifetime estimate from the failure report, then the point estimate failure rate is 0.5 /monitor-year. The initial type of monitor was changed out in mid-1989. The new units seem to work somewhat better, although they may only make about 3 years operating life ( 3 of 14 have failed as of August, 1992), or a failure rate of 0.3 /monitor-year. Using the failure rate of 0.5 /monitor-year from the operating life estimate in the failure report narrative is conservative. An upper bound for the oxygen monitor estimated lifetime might be 1 /monitor-year.

The demand failure rate for a glovebox failing to adequately contain small tritium leaks from piping inside the glovebox has been calculated from information about TSTA. Based on an estimate of the number of small tritium leaks encountered each year from TSTA piping (between 1 and 5 each year), and the recorded number of small tritium leaks to the experiment room ( 3 events), we find that the probability of glovebox failure is 5E-03/demand to confine tritium. The details of this estimate are given in Appendix $D$.

Other failure rate or failure probability estimates, such as the glovebox failure probability following an interior explosion, are discussed in Appendix D. 


\section{RESULTS COMPARISON TO OTHER GLOVEBOX EXPERIENCES}

A computerized literature search was conducted at the Idaho National Engineering Laboratory to locate other safety and reliability information about gloveboxes, to compare literature values to the TSTA results. The literature search did not identify any reports that explicitly dealt with glovebox failure rates. There were citations regarding glovebox design and operations suggestions, and a few isolated accident events, such as those described in reference 14. We cannot compare these TSTA results to other values since there are no other readily available results.

Gloves. Operating experience discussions about gloves were found in the literature search. These two reports described glove longevity, mainly in plutonium and other fission-related operations. 16.17

McFal1 ${ }^{16}$ reported that on the order of 55 pairs of gloves would be replaced each month out of the 329 pairs in use at the facility, or a point estimate failure rate of about $2 /$ glove-year. McFall also stated that the hands of the gloves were usually the area of damage; pin holes in the fingertips, cuts from handling sharp objects, etc. Conversely, Greenhalgh ${ }^{17}$ reported that the damage was usually along the glove length or at the gloveport rim. The gloves that Greenhalgh surveyed lasted a typical 136 days, or a rough failure rate of $2.7 / g$ love-year. These values are all much higher, by factors of 40 or more, than the $0.05 / g l o v e-y e a r$ value calculated from TSTA experiences.

It is reasonable to find these higher glove failure rates reported, since the glove experiences that have been discussed came from much more harsh applications than those found at TSTA. The nuclear fission fuel fabrication gloves were exposed to much more rigorous service, including: alpha radiation, heat, higher usage factors, ozone deterioration, and more variety of mechanical operations being performed inside the gloveboxes (cutting, grindiry, etc.). The glove materials were not always the thick hypalon like the gloves found at TSTA. Sometimes the gloves were neoprene, and were often the $0.4-\mathrm{mm}$ thickness rather than the $0.76-\mathrm{mm}$ thickness. Nonetheless, there is a small concern at TSTA that no ozone makes its way into the gloveboxes, so that the hypalon gloves do not become embrittled by ozone attack. 
TSTA gloves have performed well over the last eight years. There is no suggestion from the data that hypalon or butyl is a better material, or that thicker gloves significantly contribute to the difference in failure rates obtained from the fission facilities. Some glove information suggests that butyl is a better material to reduce permeation. ${ }^{18}$

TSTA personnel cannot confrim this, but they note that brand new hypalon gloves tend to allow some small amount of tritium migration for perhaps a week or so, until they become 'saturated'.15 The comparison of JFCU thinner-walled butyl glove failure rates to the TSTA thicker hypalon glove failure rates are not conclusive, because the JFCU glovebox gloves are not subject to as much rim wear from passersby as the TSTA gloves. If rim wear is not counted for hypalon gloves, the failure rates are rather close, certainly within statistical margin of each other. The major problem of excessive wear at the glove port rims is being given attention to reduce incidents of bumping, scraping, and brushing by passersby, workers moving portable equipment in the area, etc. This extra attention should reduce the future glove failure rate, since almost half of the reported failure events were caused by glove deterioration at the rims. The extra attention to glovebox integrity should also promote safety of TSTA, since the gloveboxes now run at slightly negative pressure and would slowly ingest air through any glove inleakage paths.

Solenoid valves. The TSTA solenoid valve failure to close failure rate comparison to other solenoid valve failure rates is given below. Comparing these solenoid valve results with failure to close point estimate failure rates from published data sources gives the following: $19.20,21$

\section{$\frac{\text { TSTA point estimate }}{6 E-06 / \text { demand }} \frac{\text { IEEE } 500 \text { value }}{9 E-07 / \text { demand }} \frac{\text { IAEA value }}{4 E-05 / \text { demand }} \quad \frac{\text { Eide value }}{5 E-04 / \text { demand }}$}

The TSTA value falls among these nuclear fission reactor data source values. It is somewhat lower than the authors expected, based on the more recent data source values, but it is certainly within reason. The TSTA valves are exercised frequently (averaging slightly more than once per hour), but in all, their service life is not very harsh. The operating temperature is only room temperature, there is no vibration, no 
conflicting command signals (when the controller was failing, it would typically fail in one way, definitely on or definitely off, not intermittent), and no high pressures.

Oxygen monitors. A published oxygen analycer failure rate from the chemical industry is given as 5.65 /year, for failure to analyze. ${ }^{22}$ Compared to the assumed TSTA analyzer failure rate of 0.5 /monitor-year from the narrative of report 243 , the chemical industry value is over ten times higher. A possible explanation is that the typical chemical plant environment is much more harsh than the TSTA environment. There can be high room temperatures, dust intrusion, high pressure environments to sample, sensing line plugging from foreign materials, and other failure inducing causes that TSTA equipment will not typically experience. These factors could cause such a high discrepancy in the two failure rates. 


\section{REFERENCES}

1. W. J. Brynda et al., Nonreactor Nuclear Facilities: Standards and Criteria Guide, DOE/TIC-11603-Rev. 1, BNL 51444-Rev. 1, Science Applications International Corporation, La Jolla, CA, September 1986.

2. M. A. Casey et a1., "The Data Collection System for Failure/Maintenance at the Tritium Systems Test Assembly, "Fusion Technology, 12, May 1988, pages 962-965.

3. J. J. Manning et al., CREDO News: A Quarterly Information Bullet in Issued by the Centralized Reliability Data Organization, ORNL/TM-10101/V1, Mart in Marietta Energy Systems, Inc., Volume. 1, Number 1, July 1986.

4. K. M. Gruetzmacher and R. C. Wilhelm, "Data Base for Failure/Maintenance at the Tritium Systems Test Assembiy, "Fusion Technology, 10, November 1986, pages 1596-1601.

5. K: M. Gruetzmacher, Failure/Maintenance Data Base for the Tritium Systems Test Assembly, UWFDM-653, Madison, WI: University of Wisconsin, December 1985.

6. J. R. Bartlit, "The Tritium Systems Test Assembly at Los Alamos National Laboratory, " Fusion Engineering and Design, 12, 1990, pages 393-402.

7. J. L. Anderson et al., "Some Tips on Tritium Technology," Fusion Technology, 8, September 1985, pages 2413-2419.

8. D. 0. Coffin, "The Safety Record at the Tritium Systems Test Assembly," Fusion Technology, 14, September 1988, pages 893-898.

9. Tritium Systems Test Assembly, System Design Description, Secondary Containment System, TTA-SDD-117, revision 6, August 1990.

10. J. C. Miller, TSTA instrumentation specialist, private communication, Apri1 2, 1992.

11. S. K. Sood et al., "Fusion Technology Experience at Ontario Hydro's Darlington Tritium Removal Facility and Heavy Water Upgrades," Fusion Engineering and Design, 12, 1990, pages 365-371.

12. L. C. Cadwallader and M. A. Stolpe Gavett, Iritium Waste Treatment System Component Failure Data Analys is From June 18, 1984 to December 31, 1989, EGG-FSP-8973, revision 1, also LANL LA-UR 90-2993, November 1990 .

13. G. N. Wal on et al., editors, Glove Boxes and Shielded Cells for Handling Radioactive Materials, Academic Press, New York, 1958, Chapter 1.

14. D. C. Hunt, "Restricted Release of Plutonium - Part 1. Observational Data," Nuclear Safety, 12, March-April 1971, pages 85-89. 
15. M. A. King, TSTA Secondary Confinement System operator, private communications between March 25 and Apri1 8, 1992.

16. E. D. McFal1, Glove Experience at Battelle-Northwest, BNWL-SA-5241, Battelle-Northwest Lab, April 30, 1974.

17. W. 0. Greenlialgh et al., Glovebox Glove Deterioration in the Hanford Engineering Development Laboratory Fuel Fabrication Facility, HEDL-TME 79-16, Hanford Engineering Development Lab, July 1979.

18. R. E. Giebel, "Glovebox Gloves," Proceedings of the Rocky Flats Symposium on Safety in Plutonium Handling Facilities, CONF-710401, US Atomic Energy Commission, April 13-16, 1971, pages 44-55.

19. Institute of Electrical and Electronics Engineers, IEEE Guide to the Collection and Presentation of Electrical. Electronic, Sensing Component, and Mechanical Equipment Reliability Data for Nuclear-Power Generating Stations, IEEE Std 500-1984, December 1983, page 448.

20. Component Reliability Data for Use in Probabilistic Safety Assessment, IAEA-TECDOC-478, International Atomic Energy Agency, Vienna, Austria, October 1988, page 294.

21. S. A. Eide et al., Generic Component Failure Data Base for Light Water and Liquid Sodium Reactor PRAS, EGG-SSRE-8875, EG\&G Idaho, Inc., February 1990, page 11 .

22. S. N. Anyakora et al., "Some Data on the Reliability of Instruments in the Chemical Plant Environment," The Chemical Engineer, No. 255, November 1971, pages 396-402. 
APPENDIX A

STATISTICS FOR FAILURE RATES

$A-1$ 
APPENDIX A

\section{STATISTICS FOR FAILURE RATES}

The failure rates for Tritium Systems Test Assembly (TSTA) gloveboxes were calculated. The failure rates per operating year for several different failure modes were determined.

The run-time (yearly) failures were modelled as poisson random variables. The Poisson distribution results from counting the number of failures in a fixed operating time period, when the numbers of failures in non-overlapping time intervals are independent. This distribution is well suited for time dependent failure rate calculations.

Several notes should be made about the calculations:

The total number of operating years was used, not counting the small downtimes for glovebox maintenance, or maintenance on components housed inside the gloveboxes. If any time was iost, it was on the order of less than 160 hours per glovebox, which is less than a quarter year for the entire complement of gloveboxes at TSTA over the 8-yr time period examined. That amount of time is not significant for these calculations.

The entire calendar year of 1984 was included in the eight year facility operations estimate because there were a few glovebox failure event reports from early 1984 in the data bank. It was not possible to tell exactly when each of the gloveboxes became operational, but it appears to be conservative to include all of calendar year 1984. The first overall facility tritium run was performed at TSTA on June 25, 1984.

Because there are over a dozen gloveboxes operating for eight years, there should be enough operations time accumulated to have passed through the early failures and have a steady state failure rate. That is, these failure rates should be at the bottom of the bathtub curve for time-related failure rates. Pages 14-18 of the main report address this issue for pressure controllers. 


\section{Failure rate calculations for qloveboxes}

The point estimate, lambda, or the failure rate per operating year is, 1 ambda $=X / t=($ total number of failures) $/($ total number of operating years)

Confidence bounds for lambda are based on formulas (28.1) and (28.2) found on page 96 of reference $A-1$.

$$
\begin{aligned}
& \text { Lower 95\% Confidence Bound on lambda }=\mathrm{CL} /\left(2^{\star} t\right) \\
& \text { Upper 95\% Confidence Bound on } 1 \text { ambda }=\mathrm{CU} /\left(2^{\star} t\right)
\end{aligned}
$$

where $\quad x=$ Total number of failures for the set of components

$$
\begin{aligned}
& t=\text { Total time of operation for the set of components } \\
& C L=\text { Lower Chi-squared statistic }=\text { chi-squared }(.05,2 * X)
\end{aligned}
$$

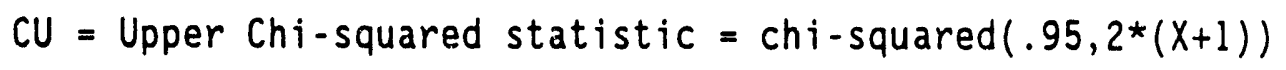

From Table 1 of the main document, the total time, $t$, all of the TSTA gloveboxes operated, is 79 years. This is conservative, since the years were rounded down to the nearest complete year. Failure counts for the failure modes of interest are taken from Table 2 in the main report:

$X=26$ failures of glovebox pressure control in overpressure

$X=15$ failures of glovebox pressure control in underpressure

$X=3$ failures in continuous purge mode

$X=2$ failures of air inleakage [note, only 1 year of TSTA operation at negative pressure]

$X=3$ failures of small tritium releases from gloveboxes

$t=79$ accumulated glovebox-years over 8 years of TSTA operations

$t=13$ accumulated glovebox-years for air inleakage events 
For the overpressure failure mode, the failure rate is:

Lambda [overpressure] $=X / t=26 / 79=0.3$ failures $/$ year

Upper $95 \%$ Confidence Bound $=67.5 /(2 \star 79)=0.4$ failures $/$ year

Therefore, the failure rate for the old pressure control system on the gloveboxes in the overpressure failure mode is $3 E-01 /$ year, and the $95 \%$ upper confidence interval bound is 0.4 /year.

For the air inleakage failure mode, the failure rate is:

Lambda [air inleakage] $=\mathrm{X} / \mathrm{t}=2 / 13=0.2 /$ glovebox - year

Upper 95\% Confidence Bound $=12.6 /(2 * 13)=0.5 /$ glovebox - year

The glove failure rates were calculated in the same manner as the glvoebox failure rates. From Table 1, there were 800 glove-years of operation for the $0.76-\mathrm{mm}$ thick hypalon gloves, and the counts of failures by mode are given in Table 5 of the main text.

note: the Chi-Square distribution values were taken from reference $A-2$.

Appendix A References

A-1. N. L. Johnson and S: Kotz, Discrete Distributions, New York: John Wiley and Sons, 1969, pages 59, 96.

A-2. B. L. Amstadter, Reliability Mathematics, New York: McGraw-Hill Book Company, 1971, pp. 336-337. 


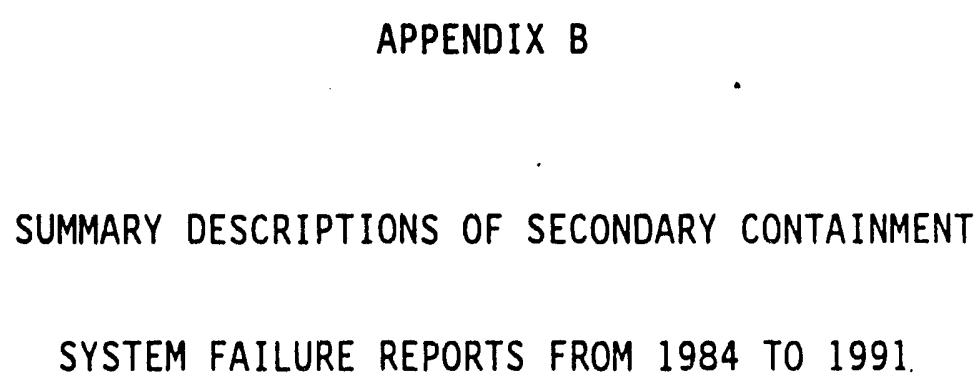

B-1 
This appendix gives brief summaries of each of the Secondary Containment System failure reports from the Tritium Systems Test Assembly. Table B-1 lists the summary information for each of the failure reports in chronological order. The report numbers, referred to as identification numbers in the main body of the report, are unique.

While TSTA began tritium operation on June 25, 1984, the construction activity for most systems was completed in 1983 or earlier. There are some failure reports from the data bank that cite glovebox problems in the early 1984 time frame. A particular report is number 005, about the house vacuum pump. On January 4, 1984, the house vacuum pump was exhausting to the Tritium Waste Treatment System (TWT) low pressure receiver tank (the same tank that all the glovebox pressure control systems exhaust to) while the TWT was undergoing some testing. A software control problem caused the pump to run on, disrupting the low pressure receiver flow from the gloveboxes. Since this was not a glovebox problem, it was not included in this appendix.

Perhaps not all gloveboxes were operational at the beginning of 1984 , but several of them appear to have been in use, and others were probably in pre-operational testing. Even in pre-operational testing, the gloveboxes had to seal, and operate monitors for tritium (at least in the small experiment gloveboxes, like XCS2 and GAN), oxygen, and internal pressure changes. The assumption about operating time should be good for statistics purposes, because even if the gloveboxes did not all start up until June 1984, they have operated into the first half of calendar year 1992 without any additional incidents that have not already been incorporated into the failure counts. 


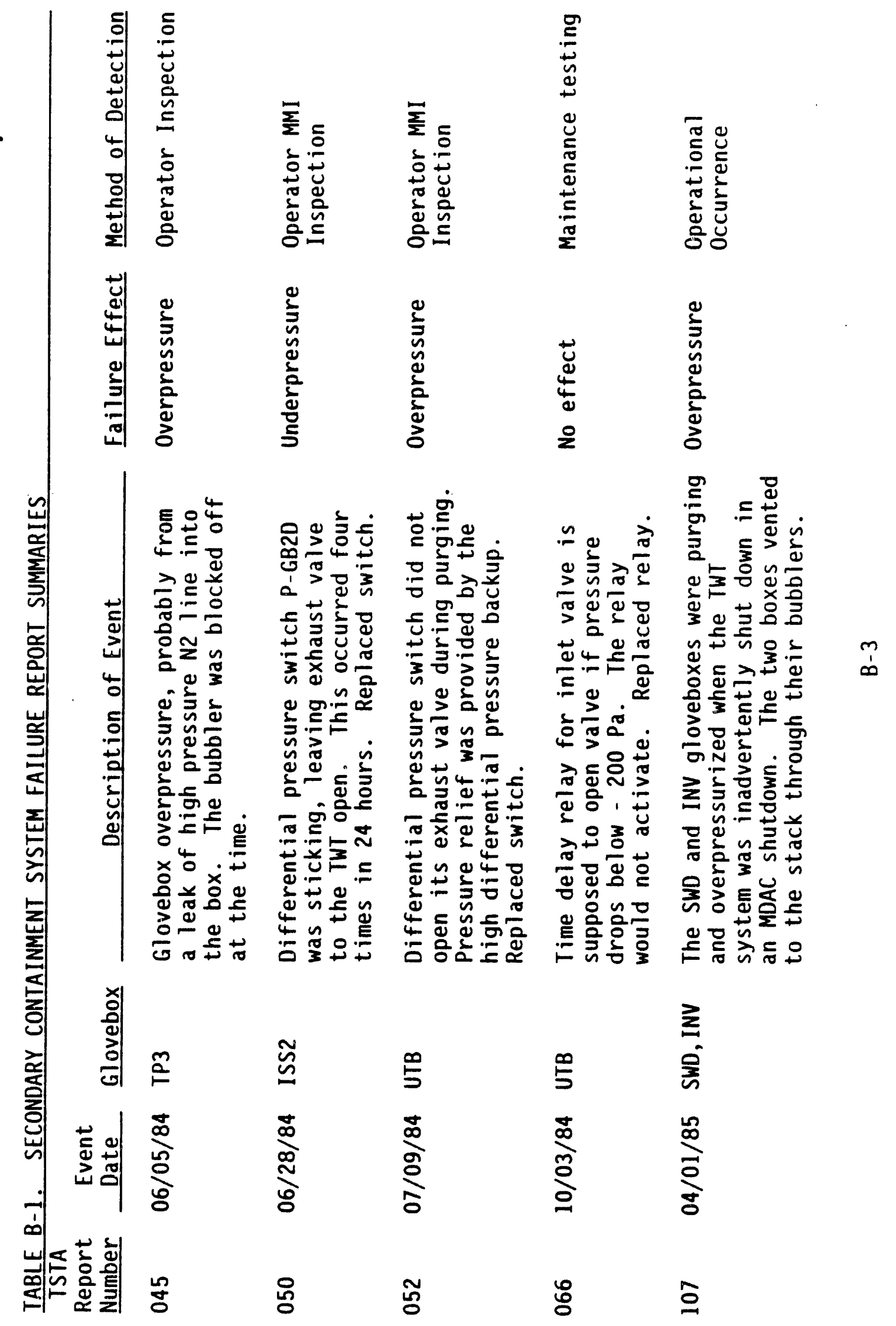




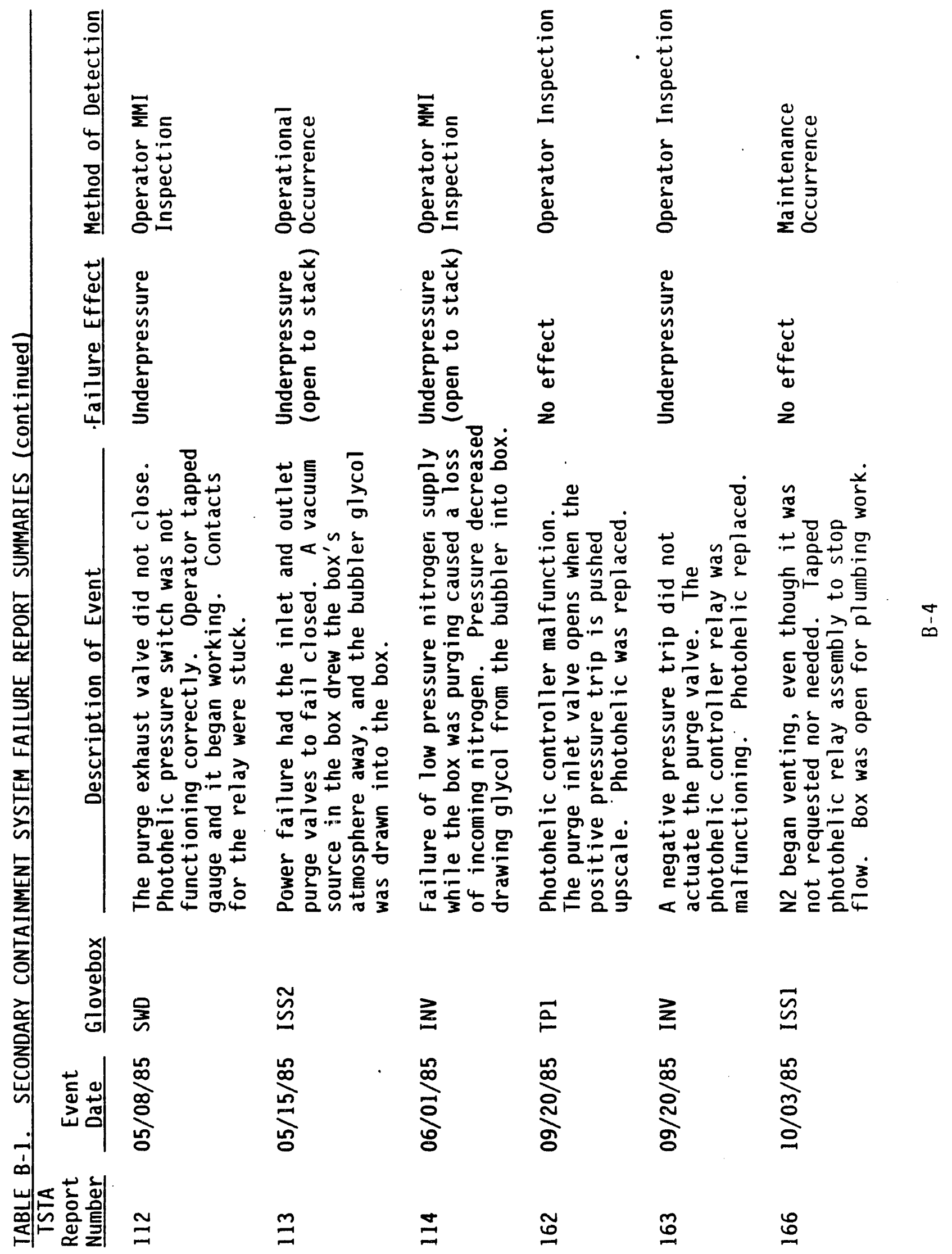




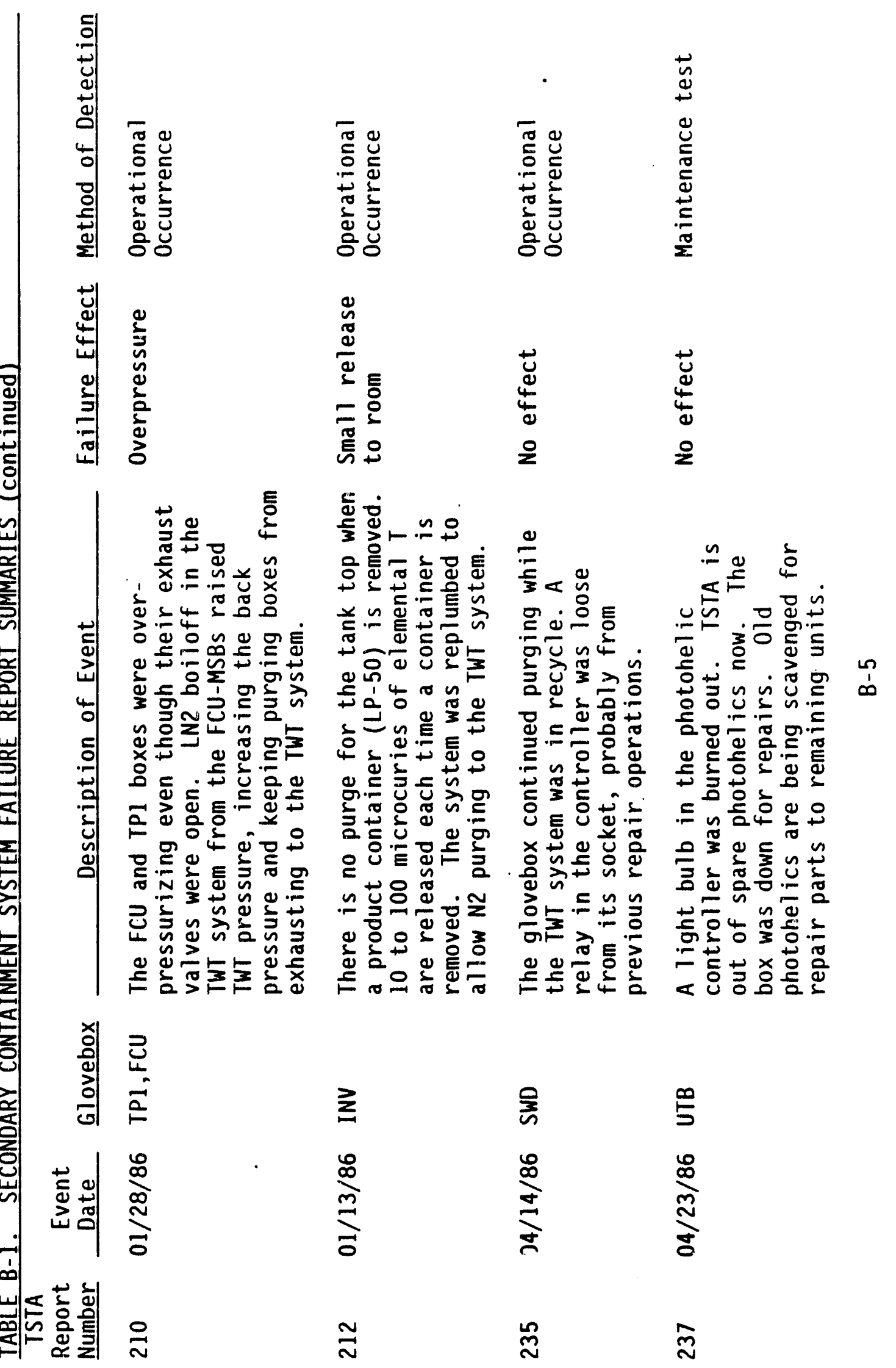




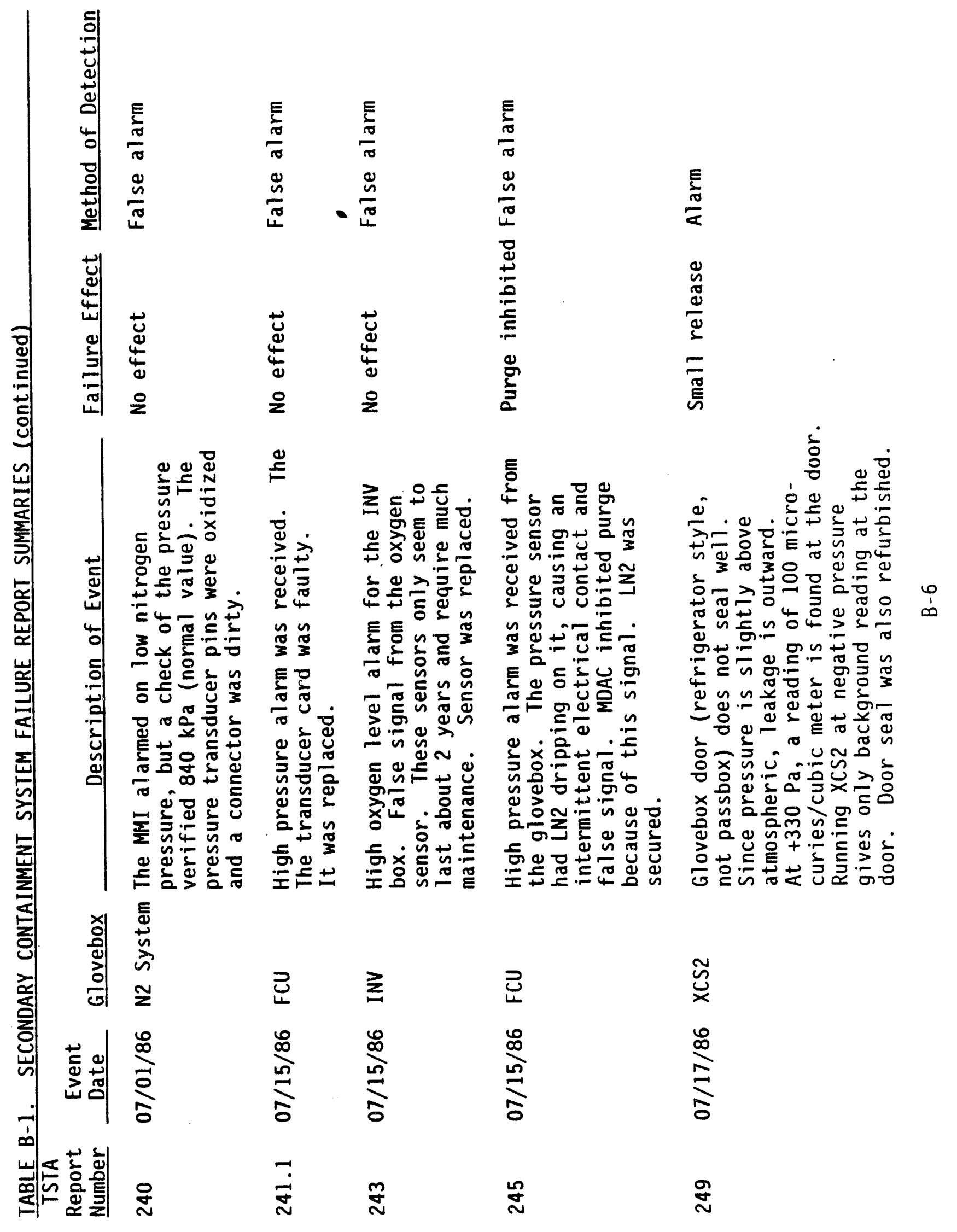




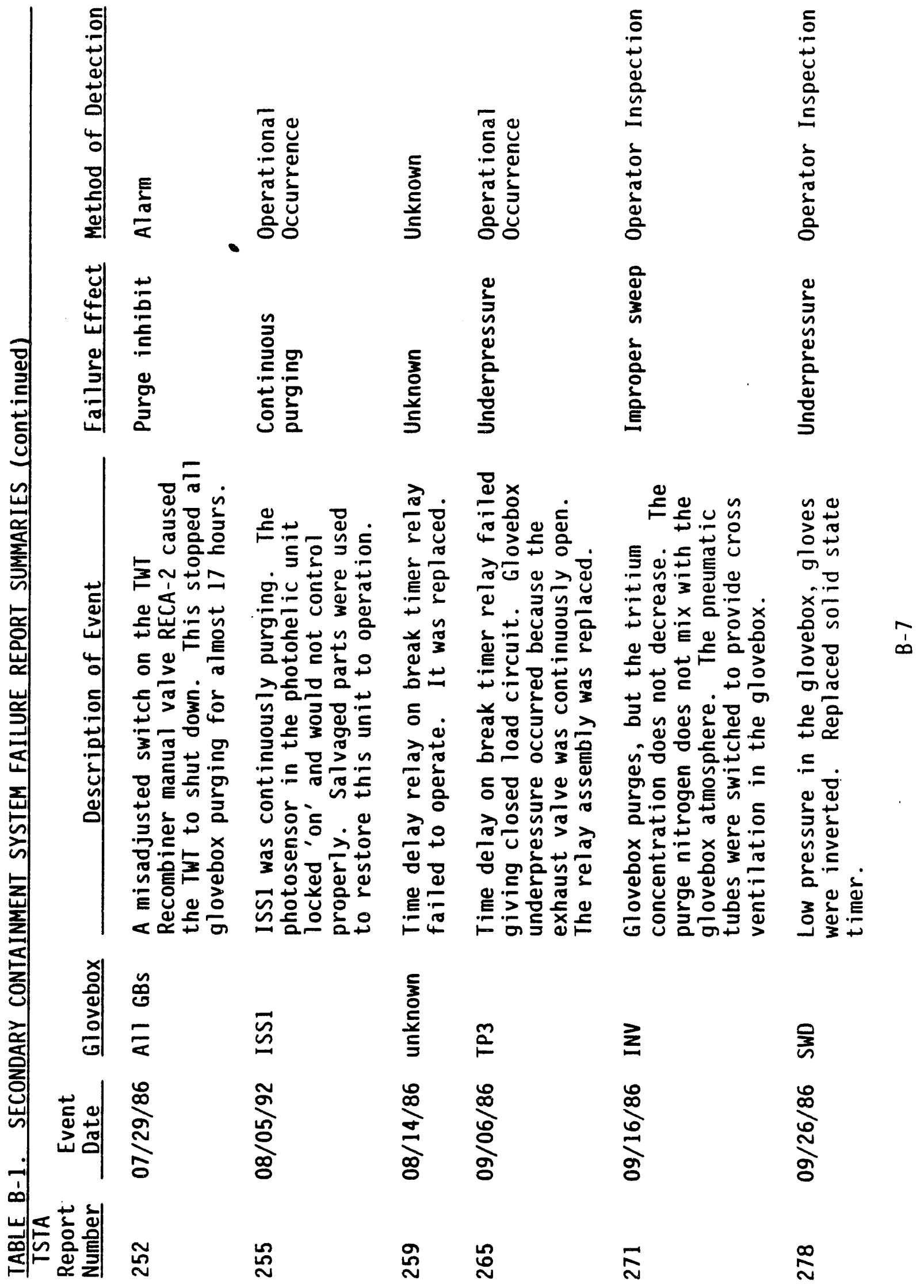




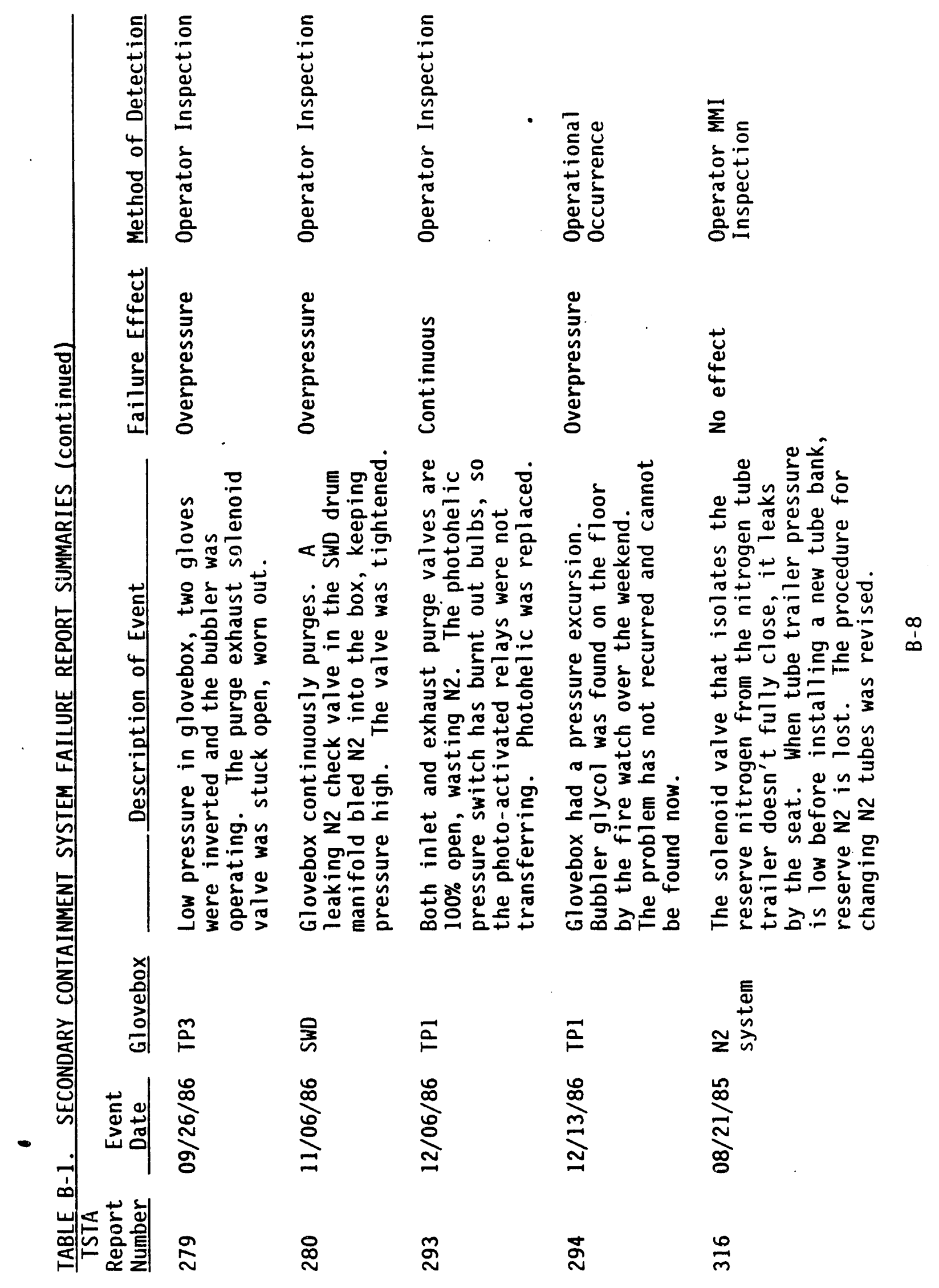




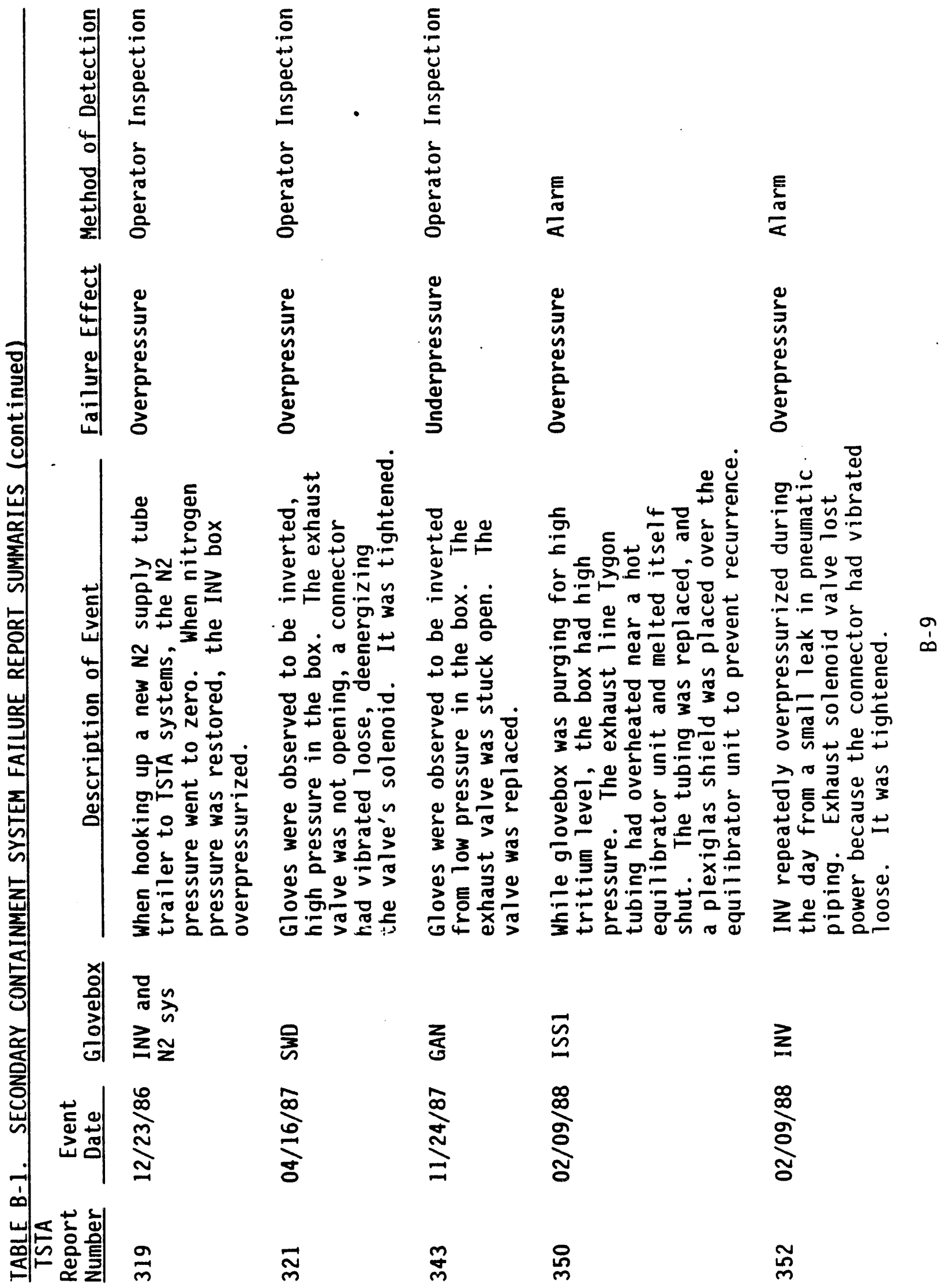









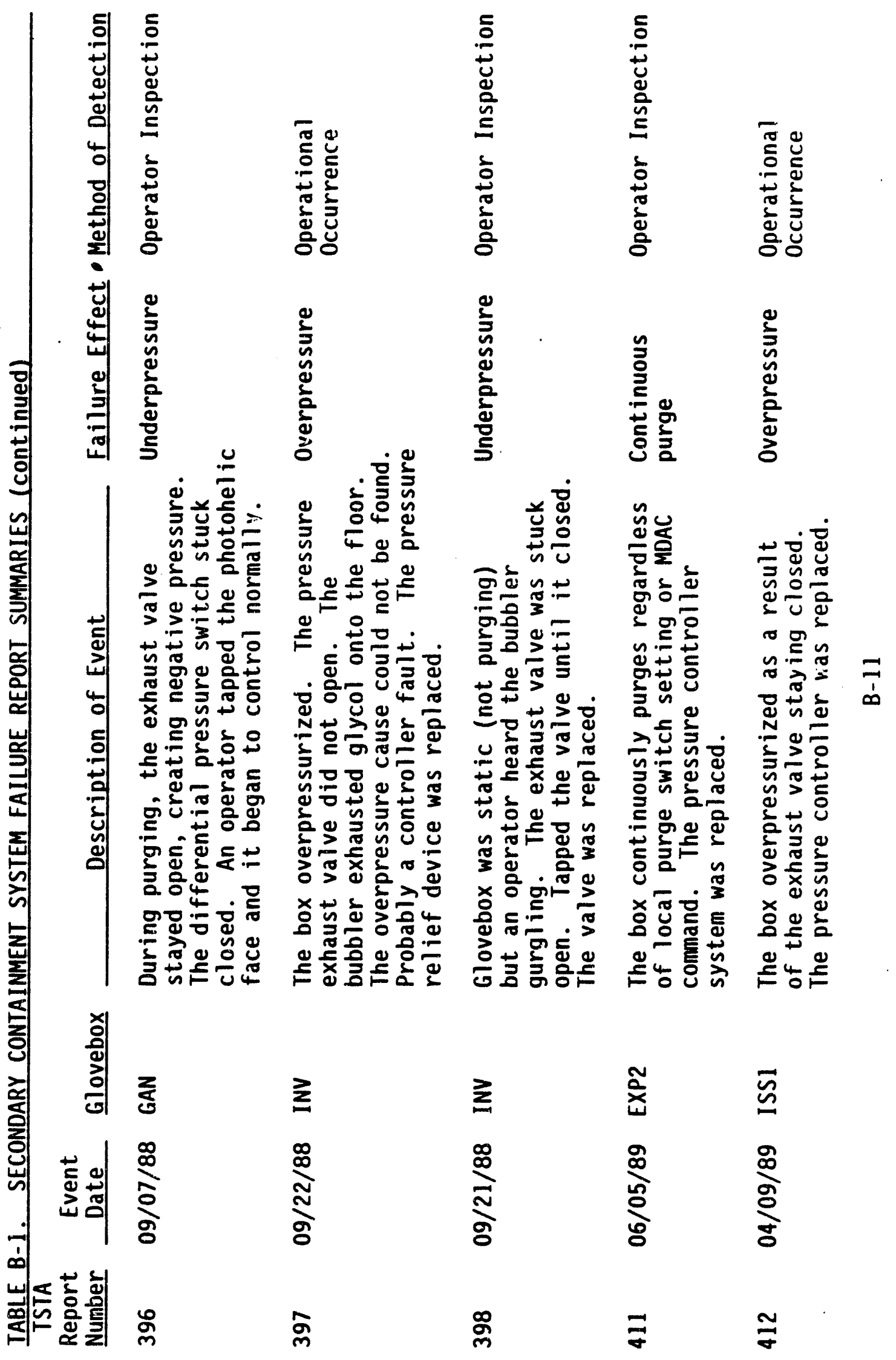




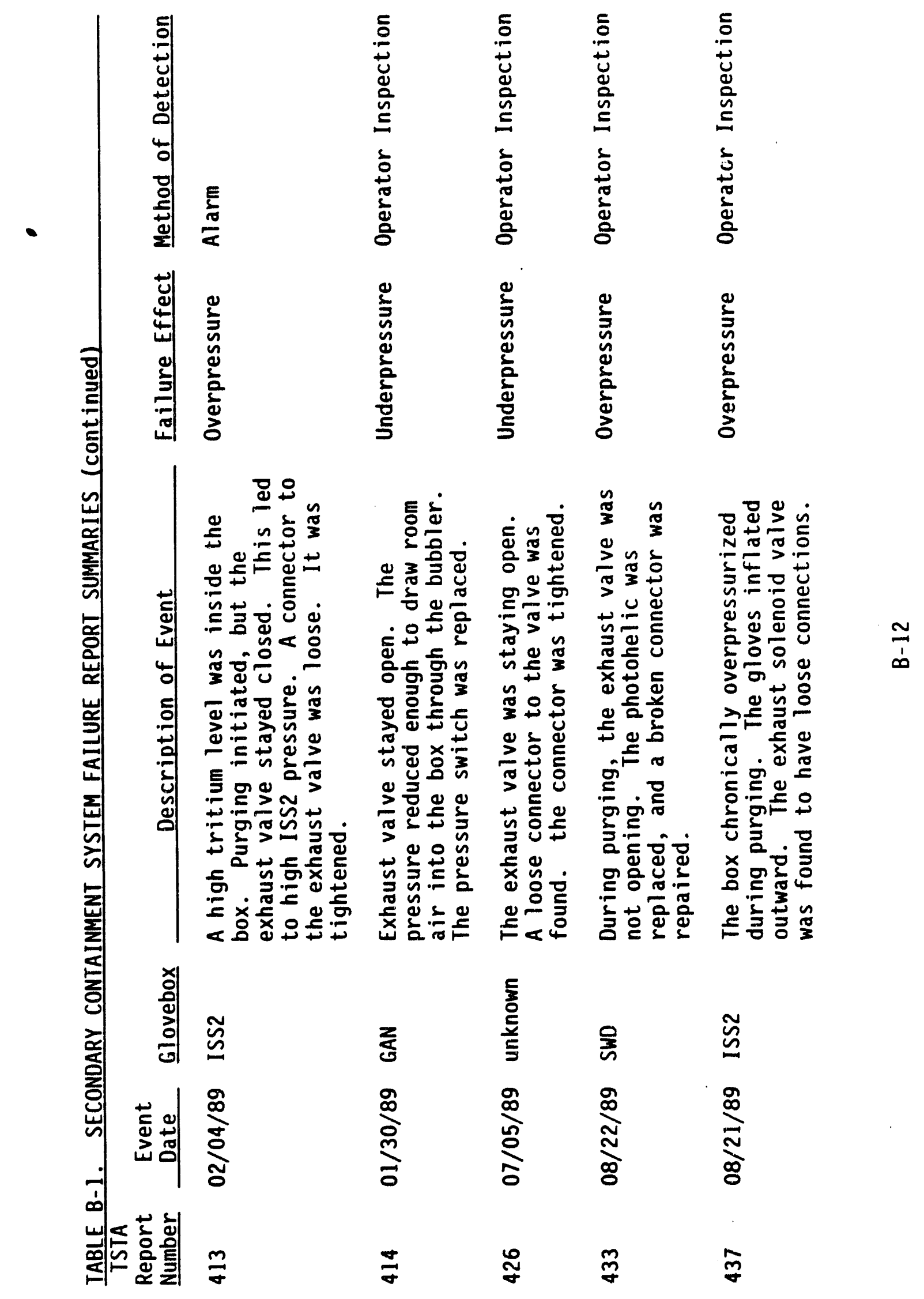




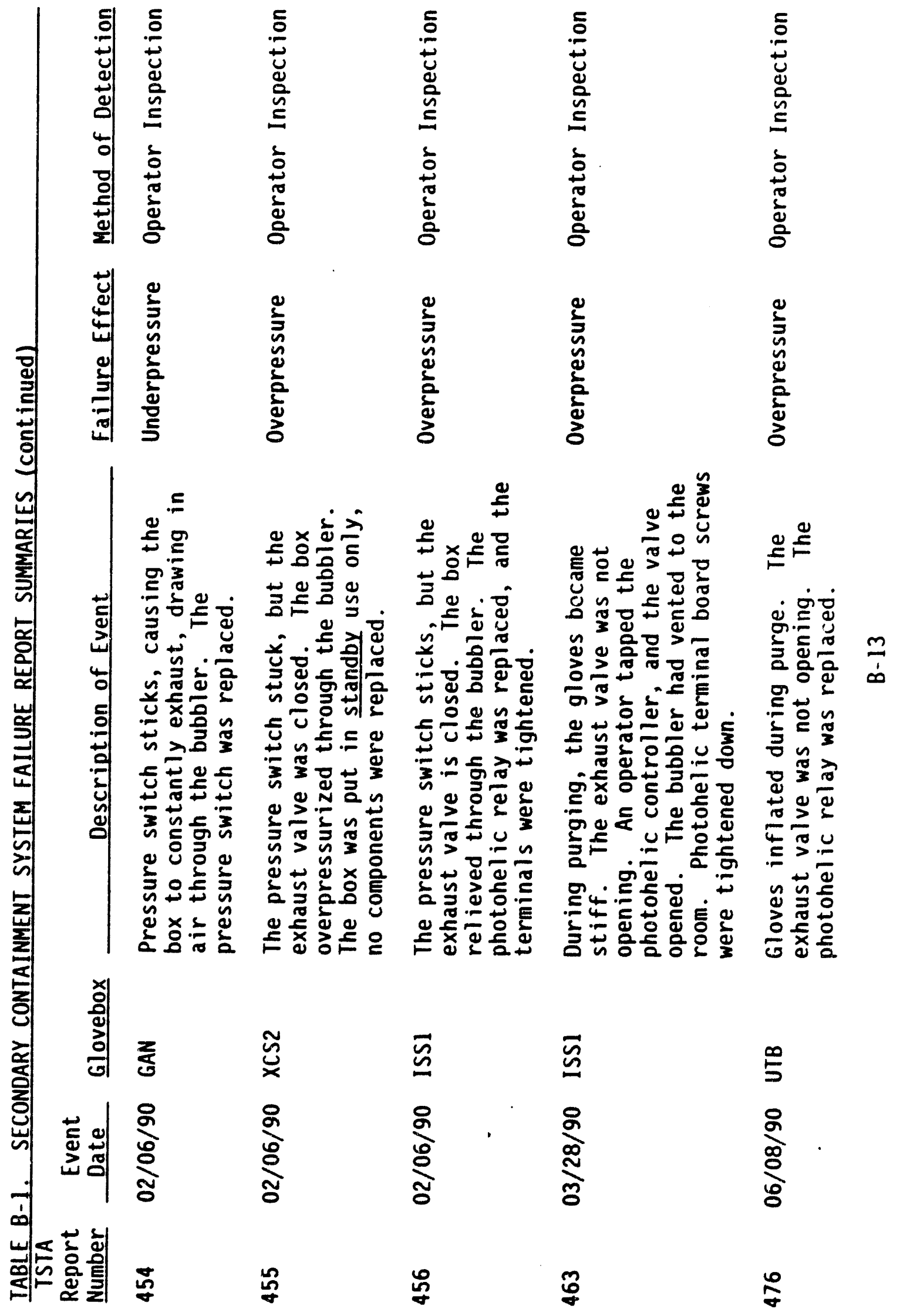




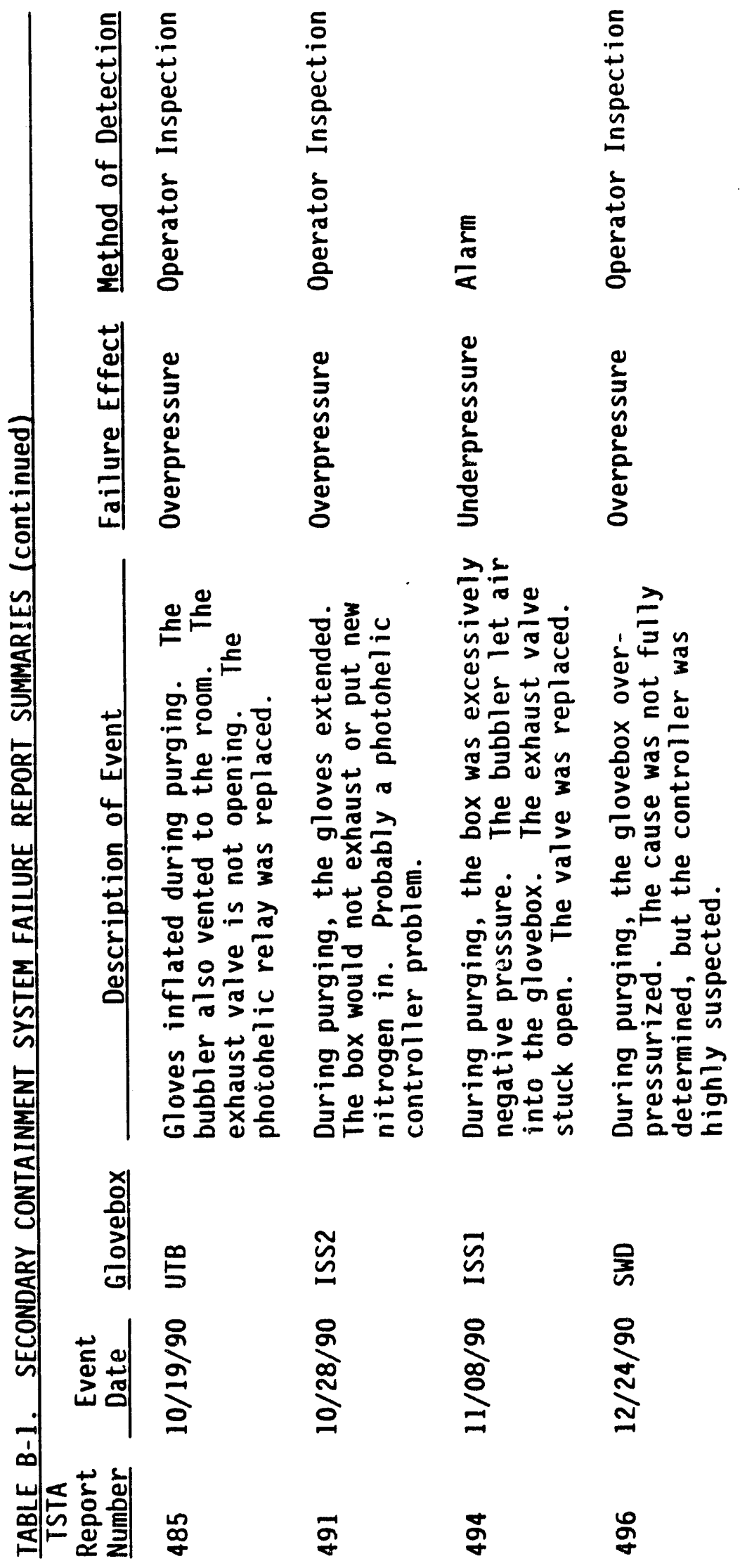




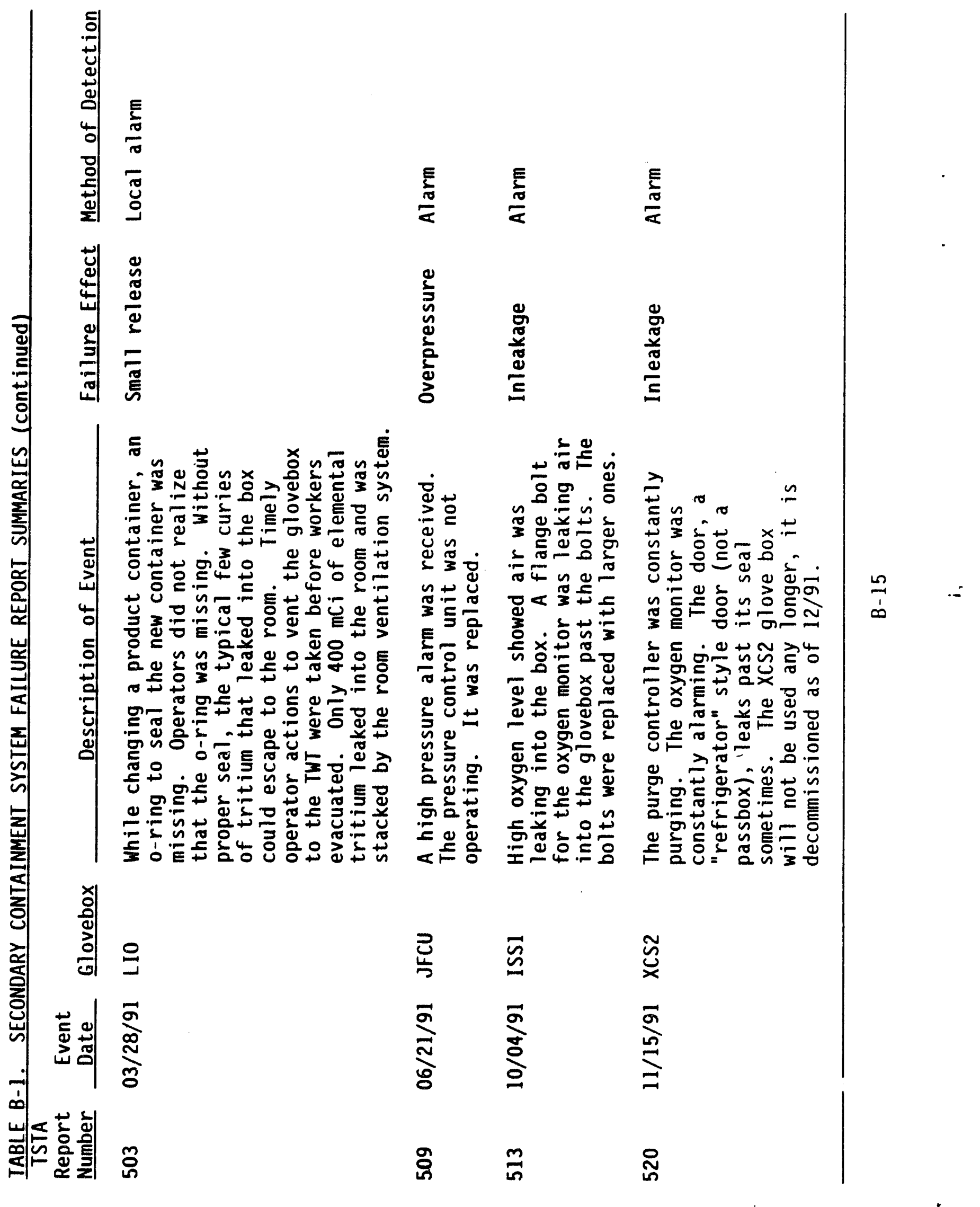




\section{APPENDIX C \\ TRITIUM SYSTEMS TEST ASSEMBLY \\ FAILURE/MAINTENANCE DATA FORMS}

$C-1$ 


\section{APPENDIX C}

TRITIUM SYSTEMS TEST ASSEMBLY FAILURE/MAINTENANCE DATA FORMS

This appendix shows examples of the data collection forms that are placed in strategic locations around the facility. The part I and part II forms are shown. More information about these forms is found in the main report and its references. 
Subsysiem Originator Repor Date

TSTA Parameter No. or Name Event Date Event Time

Subsystem Parameters at Time of Failure

Subsystem Configuration at Time of Failure

Method of Detection

Occurrence Title

Event Narrative

Initial (Immediate) Action

COMPONENT FAILURE DATA (Originator - complete the remainder of this form as fully as possible)

Component Description

Cause: Soltware _ Personnel _ Material _ Design _ Procedure _ Other (Specify)

Failure Cause Narrative

Failure Elfects: Subsystem:

Hours Lost

Unit:

Hours Lost

Other ltems Affected:

Proposed Long-Term Corrective Action

Remarks

TSTA Report Number (filled in by QA) 
TSTA FAILURE AND CORRECTIVE MAINTENANCE REPORT FORM 2

TSTA Repor Number (filled in by $Q A$ ) Correcuve Action Taken: Corrected by TSTA Operational Personnel Corrected by TSTA Repair/Design Personnel Other (Specify)

Fuiled Component Serial Number Model Number

Critical Part (s)

Problem with Component: Electrical _ Mechanical Software Other (Specify)

Duscribe Corrective Maintenance Taken to Correct Failure

Spacial Mancenance Equipment Required

Time Required for Component Repair/Replacement (hours/manhours)

(i) Total

(ii) Administrative

(iii) Logistics ___ (iv) Indirect Repair

(v) Direct Reapir

(vi) Retest

(vii) Restar

Time Since Last

(1) Maintenance

(ii) Testing

Unusual Circumstances Causing Long or Shor Repair/Replacement Time:

Assessibility Size and Weight of Component Connections Contamination (Level Other (Specify)

.Method Used for Verification of System Operational Status

By 
APPENDIX D

SOME SAFETY CALCULATIONS FOR TSTA GLOVEBOXES

D-1 
This appendix gives guidance for several particular glovebox failure probabilities, based on the Tritium Systems Test Assembly (TSTA) gloveboxes. There are two important failures that a tritium-containing glovebox can suffer. The first is an explosion or other form of severe overpressure (perhaps cryogen boiloff, etc.), and the second is any form of independent breach failure when the glovebox is called on to confine tritium that has leaked from piping, fittings, vessels, etc., into the glovebox. Therefore, the failures of concern are: glovebox failure by severe overpressure, and glovebox failure to confine process materials on demand. We also examine tritium release probability during loading and unloading operations.

\section{Glovebox Response to Explosion or Severe Overpressure}

This glovebox failure mode can be treated deterministically, in the same manner of building flood analysis. Just as certain equipment will fail with a probability of 1.0 when water rises to immerse it, a glovebox will also fail with a probability of 1.0 when certain conditions are met. Most tritium-related gloveboxes are designed with hypalon gloves and lexan polycarbonate windows. Of course, other materials might be used instead, but these appear to be a preferred choice of materials when there are no cost or other constraints on the design. We will examine the overpressure required to breach lexan windows and hypalon gloves in this section.

Lexan is noted for its engineering and safety qualities. It is a relatively strong plastic, it does not appreciably 'yellow' with age or radiation exposure, and it is a reasonable and adequate shield material. There have been studies performed for lexan as a shield material against both high velocity (blunt bodies, like valves, do penetrate $9.5 \mathrm{~mm}$-thick 1 xan sheets at $39 \mathrm{~m} / \mathrm{s}$ velocity) and hypervelocity projectiles, and the results are positive that lexan or layered lexan could serve many purposes in a variety of designs. ${ }^{0-1,0-2}$ 
TSTA documents state that differential overpressure of $6.7 \mathrm{kPa}$ (50 Torr) will likely burst a glove or breach a glovebox; therefore, there is a design feature of an overpressure relief bubbler to vent to the stack so that glovebox integrity is maintained under all circumstances. ${ }^{0-3}$.

An informal rule at TSTA is that $33.5 \mathrm{kPa}$ (250 Torr) differential pressure is considered to be the minimum pressure to breach the glovebox window. ${ }^{0-4}$ However, coarse calculations give smaller pressure values. Conversations with members of the TSTA operations staff who have witnessed glovebox accident events in other facilities support the assumption that quick-acting dynamic pressure pulses load the window before the gloves themselves are ever challenged, although the staff noted that exceptionally thick windows (over $25 \mathrm{~mm}$ thick) would allow the gloves to be challenged. ${ }^{D-5}$

Considering that the lexan window will see the increased differential pressure, a quick approximation can be performed for the lexan to find the overpressure that will crack the window. The typical TSTA glovebox window size is $1.1 \mathrm{~m}$ by $0.8 \mathrm{~m}$, and it is $6.4 \mathrm{~mm}$ thick. The polycarbonate will definitely fail before the aluminum or stainless steel body because it has a much lower yield strength (by a factor of 5 and more) than the metals. As a first approximation, considering the window to be a simply supported plate with a uniform, normal-acting load allows us to apply this stress equation:

Maximum stress at the center $=($ beta $)(a)(b)^{2}$

$$
(t)^{2}
$$

where beta $=a$ factor based on the aspect ratio of the window, in this case, $1.1 / 0.8=$ about 1.4 , so beta $=0.453$

$$
\begin{aligned}
& \mathrm{q} \quad=\text { load per unit area; recal1 } 6895 \mathrm{~N} / \mathrm{m}^{2}=50 \text { Torr } \\
& \mathrm{b} \quad=\text { length of window, in meters, in this case } \mathrm{b}=1.1 \mathrm{~m} \\
& \mathrm{t} \quad=\text { window thickness, } t=0.0064 \mathrm{~m}
\end{aligned}
$$

This formula comes from reference $D-6$. Setting the maximum stress at the center of the window to be equal to the yield stress for lexan, about $62 \mathrm{MPa},{ }^{0-7}$ allows calculation of the differential pressure, $q$. 
Using the yield stress value should result in a minimum overpressure that causes the beginning of through cracking (which leads to catastrophic glovebox breach). Solving for the differential pressure gives us $8.8 \mathrm{kPa}$, or about 64 Torr. Therefore, as a first approximation, the assumption that a sudden application of 50 Torr differential pressure can breach the glovebox is conservative, although the effect of glove ports have not been taken into account. The two or more glove ports in the lexan will serve as stress risers. Also, for quick acting pressure pulses, like a hydrogen combustion event that acts in milliseconds, the dynamic impact should also be accounted for. A dynamic loading factor of 2 should be conservative for all cases encountered with tritium gloveboxes. For hydrogen combustion events, dynamic pressures as low as $4.4 \mathrm{kPa}$ might breach the glovebox. The $8.8 \mathrm{kPa}$ value is better suited for slower acting transients, such as a high pressure line leak or cryogen boiloff inside the glovebox.

\section{Glove Response to Explosion or Severe Overpressure}

Glovebox gloves have been independently tested for their resistance to overpressure situations..$^{0-8}$ For the $0.76-\mathrm{mm}$ thick gloves, static differential pressures to cause glove bursting varied between $4 \mathrm{kPa}$ for butyl gloves, to $6.7 \mathrm{kPa}$ for neoprene, to $14.4 \mathrm{kPa}$ for polyvinyl chloride gloves. The authors of reference $D-8$ noted that dynamic pressure loadings on the gloves showed higher burst pressures than the static tests. Nearly all of the gloves failed by tearing along the sleeve, which is entirely consistent with the past military-related glovebox accident experiences TSTA operators related to the authors of this glovebox study. ${ }^{0-5}$ I assume that hapylon glove static burst pressure would be found within this given range of pressures from other glove materials. Therefore, $6.9 \mathrm{kPa}$ (about 50 Torr) is probably reasonable for a first approximation of glove failure pressure from a slow (many seconds) pressure buildup. This finding is consistent with TSTA documentation.

The results and testimony here indicate that for prompt pressure increases, in fractions of a second, the gloves will probably not be challenged, but the window will. Differential pressure pulses of $4.4 \mathrm{kPa}$ could cause through cracking, thus compromising glovebox integrity until 
repairs could be made, such as taping the cracks or replacing the window. Overpressures of such an amount and acting in such a quick time frame are not likely to be dissipated by the bubbler pressure relief system. Therefore, the probability of glovebox integrity being lost for rapid overpressure pulses above $4.4 \mathrm{kPa}$ is 1.0 . For slow overpressure transients, such as a slowly increasing (many seconds) leak from a high pressure gas line or a cryogen boiloff into a glovebox, the bubbler should keep the pressure down for a while. Eventually, pressure could build enough to pressurize the gloves, and $6.9 \mathrm{kPa}$ differential pressure is a reasonable guideline to use when assuming a glove sleeve tearing breach. In the slower overpressure transients, the gloves will be challenged before the lexan will, with its failure at or above $8.8 \mathrm{kPa}$.

The probabilities of glovebox breach in various overpressure situations is now set to be 1.0 for specific overpressure values. The safety or risk analyst must calculate the frequency of such overpressure events. The TSTA value for in-glovebox fires, explosions, or severe overpressures is $0.003 / g$ lovebox-year, as a 50\% Chi square distribution point estimate based on no events in 79 glovebox-years of TSTA operations. Since this value is only based on 8 years of experience, I expect that it would be much lower if all the world's fusion-related tritium facility experiences were analyzed.

\section{Glovebox Failing to Provide Confinement on Demand}

The glovebox is a second confinement level around the process piping in magnetic fusion applications. The glovebox must be able to confine any small leakage of tritium or tritiated water vapor, etc., if and when it leaks out of the process piping.

Past work has cited a value of 0.04 probability of glovebox failure to confine on demand, based on the availability of the TSTA Tritium Waste Treatment system to accommodate the overpressure exhaust gas. $0^{0-9}$

This probability value was later refined to an order of magnitude estimate of $0.01 /$ confinement demand for application to Burning Plasma Experiment gloveboxes. ${ }^{0-10}$ Other work from the Joint European Torus (JET) confirms this order of magnitude probability estimate of $0.01 /$ confinement 
demand for the probability of glovebox breach failure upon tritium leakage. ${ }^{0-11}$ Combined with JET analyst estimates for the frequency of releases into the gloveboxes ( 0.25 events per year per valving glovebox), a tritium release to the room would be considered an unlikely event. Other published work for the Japanese Fusion Experimental Reactor sets a probability of the glovebox failing to coifine at $6.8 \mathrm{E}-04 /$ demand, but the basis for this value was not fully explained. ${ }^{0-12}$

The TSTA experience to date is that there have been three small tritium leaks (largest was $0.4 \mathrm{Ci}$, the others were in the millicurie range) to the experiment room. These all occurred before the decision to operate the gloveboxes at slightly subatmospheric pressure. Operations since the change to subatmospheric glovebox pressure have not experienced any tritium releases from the gloveboxes. Over one year, with 13 operating gloveboxes, this gives a point estimate of about $0.02 /$ glovebox-year, compared to the $0.04 / g$ lovebox-year given in Table 4 of the main report.

To obtain an average failure probability for risk assessment usage, we assume a number of small tritium leaks from the glovebox-contained piping. Dr. J. R. Bartlit of TSTA believes that this number of small leaks is greater than $1 /$ year and less than $5 /$ year,,$^{0-13}$ so I assume one small leak/quarter year. Over seven years of initial glovebox operation at TSTA, this is a total of about 28 small leaks into gloveboxes. TSTA experience indicates that three leaks propagated outside the gloveboxes in that time. I will not count the Load In/Load Out glovebox (LIO) event (report number 503) because that event happened due to a missing o-ring seal on a tritium container, therefore, the actual glovebox unit itself was not at fault. Reports 212 (small release from the Inventory [INV] glovebox, the former LIO glovebox) and 249 (leak from the experimental contamination studies "refrigerator style" single door glovebox [XCS2]) are not counted, either, because these events occurred with special gloveboxes - the LIO again uses the product container seal as part of the glovebox seal, and the XCS2 glovebox had a single door to the room atmosphere rather than the standard airlock or passbox. In fact, the XCS2 glovebox has been removed from service because of the inleakage and outleakage problems with the "refrigerator style" door. Therefore, none of these events should be counted as typical events, such as tritium leaking from a seal or penetration. 
Since none of the actual TSTA events are considered countable, an assumed outleakage event occurring in the typical gloveboxes was used to determine conservative operating statistics. Using one small outleakage event over the time period of 7 years for the remaining gloveboxes (not counting the LIO, INV, or XCS2 boxes) gives:

1 outleak/(28 inleak events at TSTA)( 7 effective gloveboxes at TSTA) = 5E-03 probability of glovebox failure to confine when called upon at TSTA. A $95 \%$ Chi square upper bound probability would be $2 E-02$.

The 5E-03 probability should be very conservative, since the one failure was assumed, and because the value was calculated over the operating time period when the glovebox pressure was kept at static atmospheric pressure and slightly higher, rather than slightly below atmospheric pressure. Glovebox operation at negative pressure should greatly reduce this event probability. The 5E-03 probability is also between the estimated 1E-02 probability for future JET equipment and for BPX safety work, and the 6.8E-04 probability used for the Japanese Fusion Experimental Reactor design safety analysis. The 5E-03 probability value is a reasonable estimate for future safety work, given that the gloveboxes of interest are similar to those at TSTA; that is, they are equipped with bubbler overpressure protection, polycarbonate windows, and have all welded metal frames.

\section{Iritium Releases to the Experiment Room from the LIO Glovebox}

TSTA has experienced two small tritium releases to the experiment room from the load in/load out operations glovebox (report 212; $100 \mathrm{mCi}$, and report 503; $400 \mathrm{mCi}$ ). Over 8 years, there have been between 6 to 8 LIO operations per year, on average. ${ }^{0-14}$ The report 212 should not be counted when applying data to other facilities, since there was a design flaw in the nitrogen gas sweeping subsystem such that a small amount of tritium would be lost in each tritium container changeout. Future facilities would be advised to examine methods of tritium loading and unloading that do not rely on use of the tritium container itself to form a part of the glovebox confinement boundary. 
Counting the one event (report 503), a point estimate failure rate of $1 /(8$ years)( 7 evolutions per year), or about $2 E-02 / 10$ ading evolution is calculated. Therefore, the failure probability for small tritium releases during loading and unloading operations is 0.02 . The $95 \%$ chi-square upper bound would be $3 E-02 /$ loading evolution.

This probability is reasonable to use as an initial estimate for other facilities, but the features of the LIO glovebox must be kept in mind. TSTA also has strict operations procedures, which include a buddy system, that should be taken into account if this failure rate is applied to another facility. Also, since the tritium container is clamped to a bottom port of the glovebox, and the container itself forms part of the seal, these data may not be applicable to other gloveboxes. For example, gloveboxes large enough to place the tritium container into a passbox or antechamber will very likely have a lower probability of accidental tritium release to the room. 
Appendix D. References

D-1. W. H. Ciolek, "Laboratory Shielding for Projectiles," Plant/Operations Progress, I, April 1988, pages 79-86.

D-2. W. P. Schonberg, "Response of Spacecraft Window Materials to Hypervelocity Projectile Impact," Journal of Spacecraft and Rockets, 28, January-February 1991, pages 118-123.

D-3. Tritium Systems Test Assembly, Standard Operations Procedure, Secondary Containment (SEC), TTA-SOP-117-R6, revision 6, Apri1 1991.

D-4. R. D. Carlson, TSTA designer and manager, private communication, April 8, 1992.

D-5. W. Harbin and R. Pierce, TSTA operations staff members, private communication, April 7, 1992.

D-6. W. C. Young, Roark's Formulas for Stress and Strain, sixth edition, McGraw-Hi11, New York, 1989, page 458.

D-7. "Materials Reference Guide," Machine Design, 59, Apri1 16, 1987 , pages 140-141.

D-8. C. Yao et al., Evaluation of Protection from Explosion Overpressure in AEC Gloveboxes, Factory Mutual Research Corporation, FMRC Serial No 16215.1, Atomic Energy Commission contract number AT (11-1)-1393, December 1969.

D-9. S. 2. Bruske and D. F. Holl and, Risk Assessment of a Fusion Reactor Fuel Processing System, EGG-2266, EG\&G Idaho, Inc., July 1983.

D-10. D. F. Holland et al., Potential Off-Normal Events and Releases for the Burning Plasma Experiment, EGG-FSP-7872, revision 3, EG\&G Idaho, Inc., July 1991.

D-11. P. R. Ballantyne et al., "The Design Features of Secondary Containments for the JET Active Gas Handling System and Their Role in Mitigating Both Chronic and Accident Tritium Releases," Fusion Technology, 21, March 1992, pages 483-488.

D-12. Y. Seki et al., "Safety Analysis of the FER Fuel Circulating System," Fusion Engineering and Design, 10, 1989, pages 373-83.

D-13. J. R. Bartlit, TSTA manager, private conversation, March 1, 1991.

D-14. D. Hamerdinger, TSTA operator, private conversation, June 22 , 1992. 


\section{Distribution}

F. Adams, EG\&G Mound

J. L. Anderson, LANL

c. C. Baker, ORNL

J. R. Bartlit, LANL

P. Ballantyne, ORNL

A. Boschi, ENEA

S. J. Brereton, LLNL

R. Büende, IPP

G. Cambi, ENEA

M. B. Calley, EG\&G Idaho, MS 2406

R. E. Carlson, LANL

V. Chuyanov, Kurchatov

I. Cook, Culham

J. N. Doggett, LLNL

C. A. Flanagan, ORNL

R. B. Fleming, PPPL

M. Gouge, ORNL

B. Green, JET

W. Gulden, IPP

R. Hancox, Culham

W. Hedley, EG\&G Mound

S. K. Ho, UCB

J. P. Hoidren, UCB

M. S. Kazimi, MIT

I. Kirillov, Efremov

B. N. Kolbasov, Kurchatov

W. Kramer, KfK

J. Levine, PPPL

J. H. Nadier, DOE-ID, MS 1220

G. R. Nardella, DOE HQ

G. Pearson, UKAEA

P. I. Petersen, GA

S. J. Piet, EG\&G Idaho, MS 3523

R. E. Price, DOE-HQ

Y. G. Prokofiev, Efremov

J. Raeder, IPP

P. Rocco, JRC-Ispra

G. Saji, JAERI

D. Sanchez, LANL, (4)

Y. Seki, JAERI

S. Sood, CFFTP

J. S. Strebkov, Institute of Power Engineering

L. Topi iski, Kurchatov

C. Wong, GA

M. Wykes, JET 

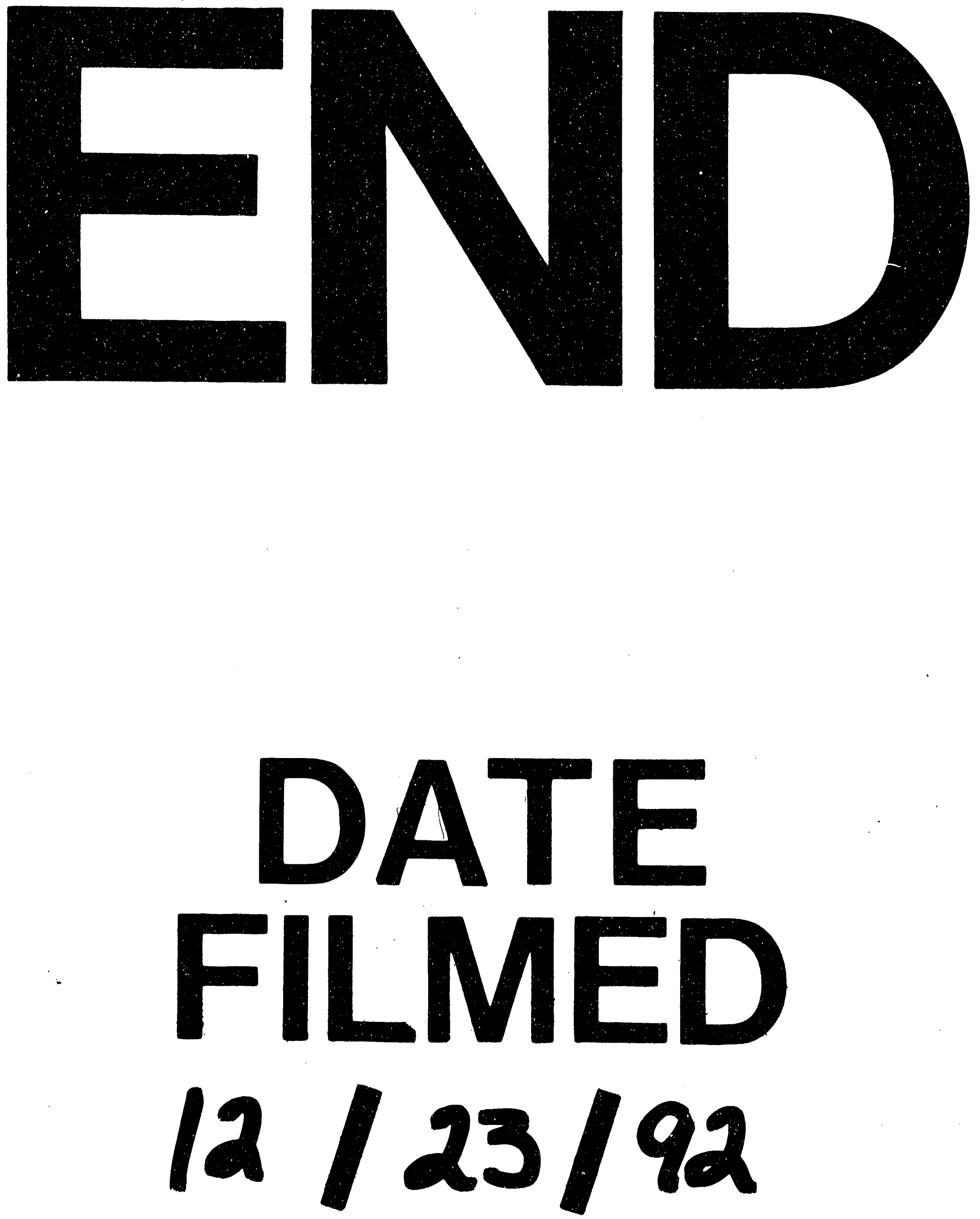
